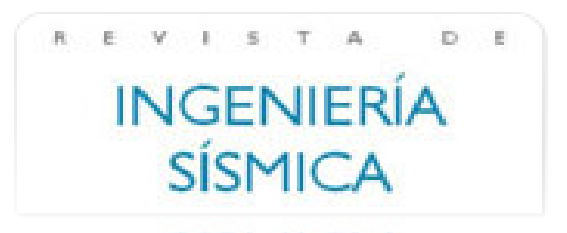

\section{Revista de Ingeniería Sísmica}

ISSN: 0185-092X

javiles@tlaloc.imta.mx

Sociedad Mexicana de Ingeniería Sísmica

México

Luna Arroyo, José Luis; Tena Colunga, Arturo

Observaciones sobre algunos criterios de diseño sísmico de edificios con marcos de concreto reforzado

Revista de Ingeniería Sísmica, núm. 66, enero-junio, 2002, pp. 1-43

Sociedad Mexicana de Ingeniería Sísmica

Distrito Federal, México

Disponible en: http://www.redalyc.org/articulo.oa?id=61806601

- Cómo citar el artículo

Número completo

- Más información del artículo

Página de la revista en redalyc.org

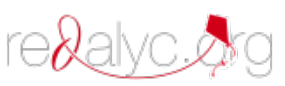

Sistema de Información Científica

Red de Revistas Científicas de América Latina, el Caribe, España y Portugal Proyecto académico sin fines de lucro, desarrollado bajo la iniciativa de acceso abierto 


\title{
OBSERVACIONES SOBRE ALGUNOS CRITERIOS DE DISEÑO SÍSMICO DE EDIFICIOS CON MARCOS DE CONCRETO REFORZADO
}

\author{
José Luis Luna Arroyo $^{(1)}$ y Arturo Tena Colunga ${ }^{(2)}$
}

\begin{abstract}
RESUMEN
Se presenta un análisis de las disposiciones de las Normas Técnicas Complementarias para Diseño y Construcción de Estructuras de Concreto (NTCC-96) del Reglamento de construcciones para el Distrito Federal (RCDF-93) basado en una comparación con diferentes reglamentos internacionales, dicha comparación se enfoca en las disposiciones para marcos dúctiles y marcos no dúctiles contemplando las diferencias desde el punto de vista conceptual, numérico e intuitivo. Se toma como base de la comparación el reglamento del ACI 318-95, ya que la mayoría de los códigos se apoyan en sus especificaciones y se analizan los reglamentos resaltando las diferencias existentes con el código base. Se presentan las diferencias más relevantes entre los reglamentos internacionales y el RCDF-93. Las formulaciones y criterios exclusivos de las NTCC-96 parecen no estar apoyados suficientemente en investigaciones analíticas o experimentales. Se hace patente que algunas de ellas, pueden llegar a complicar y a hacer tedioso el proceso de diseño injustificadamente. Se comentan algunas modificaciones a las NTCC-96 que se incluyen en la Propuesta de las Normas Técnicas Complementarias para Diseño y Construcción de Estructuras de Concreto (NTCC-2001) actualmente en evaluación.
\end{abstract}

\section{SUMMARY}

The recommendations contained in the concrete norms (NTCC-96) of Mexico's Federal District Code (RCDF-93) for special moment and ordinary moment resisting reinforced concrete (RC) frames are compared with the specifications made by other different RC international codes. This study considers the regulations of the ACI 318-95 as a base for comparison with NTCC-96. The formulations and criterions, which are exclusive for NTCC-96, are not supported by extensive analytical or experimental investigations. It is evident that some of these additional provisions could complicate and make tedious the design process of RC structures without any justification. Some changes made for the draft version of the new concrete norms (NTCC-2001) are also commented.

Artículo recibido el 9 de agosto de 2000 y aprobado para su publicación el 15 de enero de 2002. Se aceptarán comentarios y/o discusiones hasta cinco meses después de su publicación.

(1) Instituto Mexicano del Petróleo. Subdirección de Ingeniería. Competencia de Ingeniería Civil. Eje Central Lázaro Cárdenas No. 152, 07730 México, D.F. jlluna@imp.mx

(2) Universidad Autónoma Metropolitana Azcapotzalco. Departamento de Materiales. Av. San Pablo No. 180, Col. Reynosa Tamaulipas, 02200 México, D.F. atc@correo.azc.uam.mx 


\section{INTRODUCCIÓN}

Los reglamentos internacionales para diseño de estructuras de concreto presentan algunas diferencias en el rubro de diseño de marcos de concreto reforzado. A continuación se presenta una comparación entre los siguientes códigos:

- Building Code Requirements for Structural Concrete (ACI 318-95) and Commentary (ACI 318R-95), del Instituto Americano del Concreto (ACI-95, 1997).

- 1997 Uniform Building Code (UBC-97, 1997).

- New Zealand Standard: Code of Practice for the Design of Concrete Structures NZS 3101:1982 (NZS-82, 1982), complementado con Park (1995 y 1997).

- Architectural Institute of Japan: Standard for Structural Calculation of Reinforced Concrete Structures y Design Guidelines for Earthquake Resistant Reinforced Concrete Buildings Based on Ultimate Strength Concept (AIJ-90, 1994).

- Canadian Standards CAN-A23.3-M84, la revisión de este reglamento se hizo basado en Habibullah (1992).

- Normas Técnicas Complementarias para Diseño y Construcción de Estructuras de Concreto (NTCC-96, 1996) del Reglamento de Construcciones para el Distrito Federal (RCDF-93, 1993).

En el estudio original (Luna, 1999) se comparan con detalle las especificaciones relacionadas con marcos de concreto. En este trabajo la comparación se enfocará en las disposiciones para marcos dúctiles y marcos no dúctiles, contemplando las diferencias desde el punto de vista conceptual, numérico e intuitivo en el caso en que los requisitos no estén soportados en estudios o investigaciones.

\section{CONSIDERACIONES GENERALES}

\section{Suposiciones de diseño}

Los requisitos generales y suposiciones de diseño coinciden en la mayoría de los reglamentos estudiados, salvo algunas especificaciones que se extienden a considerar casos más puntuales. A continuación se presenta un resumen de algunas diferencias entre dichos requisitos:

- Las deformaciones en el acero de refuerzo y en el concreto se deben suponer directamente proporcionales a la distancia desde el eje neutro (fig. 1). Para este punto el ACI, UBC, CAN y el NZS establecen que se deberá considerar una distribución no lineal de la deformación para elementos de gran peralte sujetos a flexión, es decir, no se asumirá en este caso la distribución mostrada en la fig. 1.

- La relación entre la distribución del refuerzo por compresión en el concreto y su deformación se puede suponer que es rectangular (fig. 1), trapezoidal, parabólica o de cualquier otra forma 
que resulte de la predicción de la resistencia y que coincida sustancialmente con los resultados de pruebas a la compresión (ACI-95, 1997).

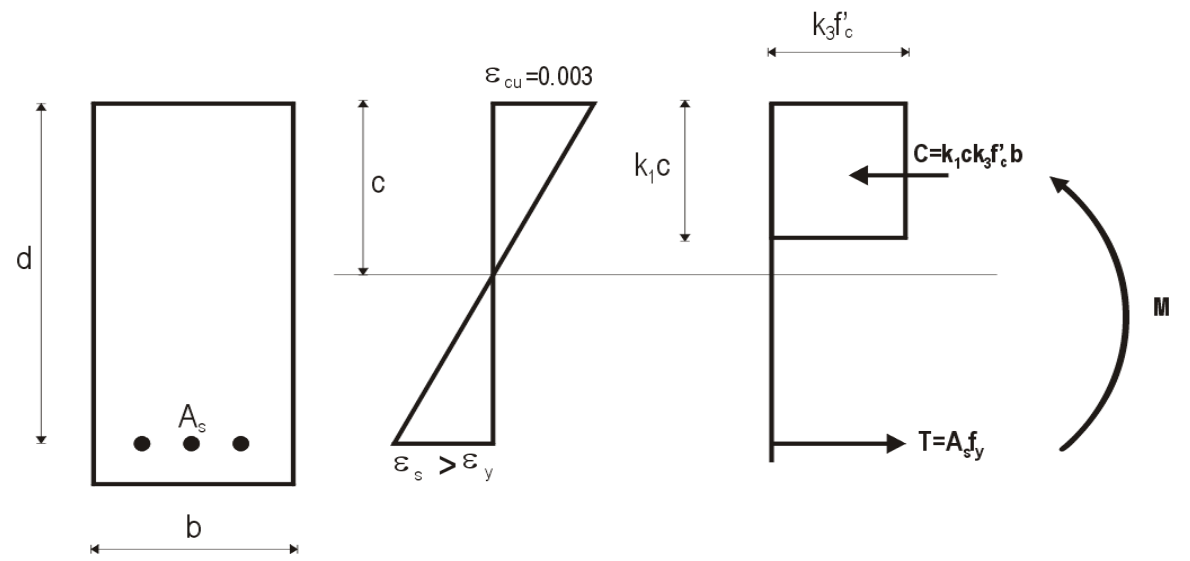

Figura 1. Hipótesis sobre la distribución de deformaciones y esfuerzos.

Las NTCC-96 no plantean esta última alternativa, únicamente dan la opción de utilizar el bloque de esfuerzos rectangular equivalente. Por otro lado, el AIJ establece un planteamiento diferente, involucrando características físicas y mecánicas del concreto y del acero y características geométricas de la sección en las condiciones de equilibrio de la misma.

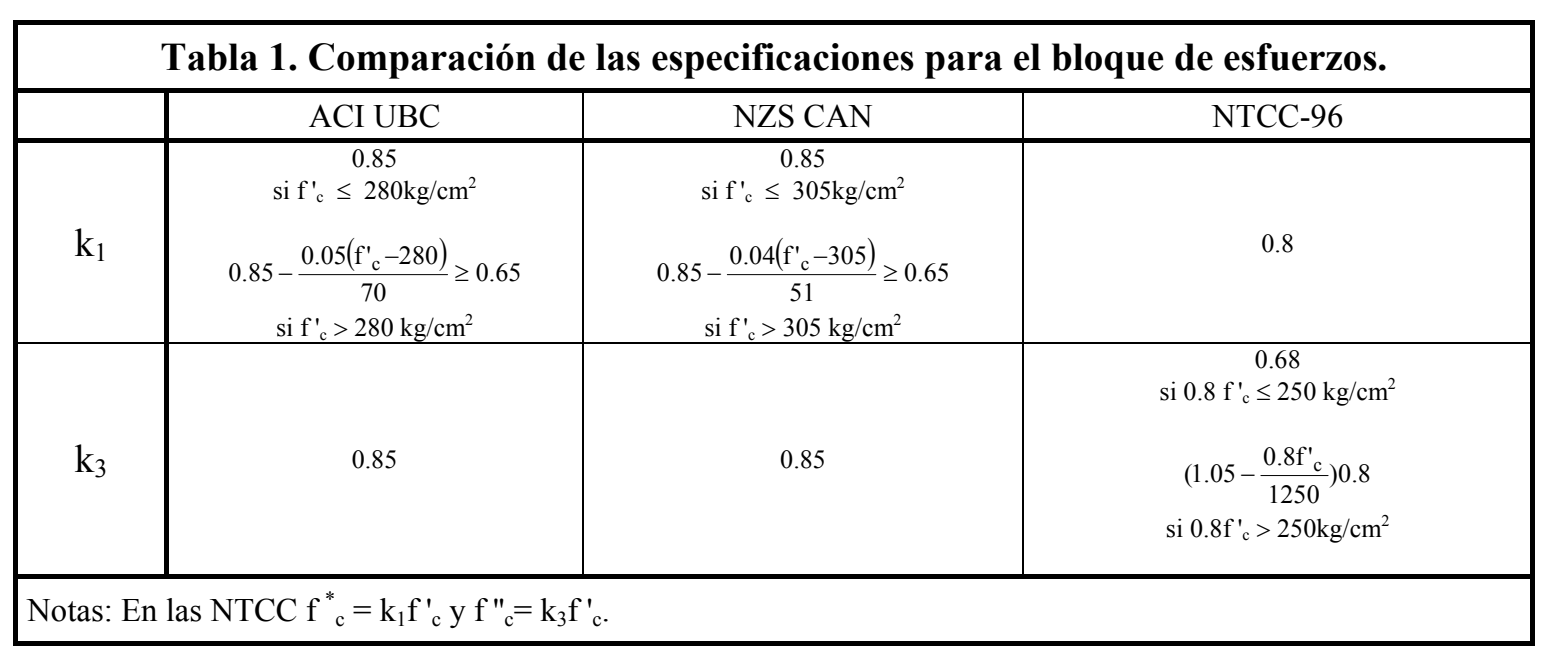

En la tabla 1 se establece la comparación de las especificaciones de cada reglamento para el bloque de esfuerzos rectangular equivalente (fig. 1), siendo éste el que coincide en la mayoría de los códigos estudiados, además de ser el más comúnmente utilizado en el diseño estructural.

A diferencia de los demás reglamentos, en las NTCC-96 se hace disminuir el esfuerzo medio de compresión del bloque de esfuerzos como función de $\mathrm{f}_{\mathrm{c}}$, en lugar de su profundidad, lo que implica que el brazo de palanca es constante. Desde el Reglamento (RCDF) de 1966 se 
adoptó este criterio, porque permite construir juegos de curvas de interacción que no dependen de $\mathrm{f}^{\prime}$ c para dimensionamiento de columnas, y conduce a resultados muy semejantes a los obtenidos con el del ACI ("Comentarios", 1991). Si se pretende que los valores sean semejantes a los del ACI, se puede comprobar que esto ocurre únicamente para el caso en que se está analizando flexión y no en flexocompresión. Analizando una columna típica de $70 \times 70 \mathrm{~cm}$ con porcentajes de refuerzo mínimo y máximo (figs. 2 y 3), se puede observar que al comparar los diagramas de interacción realizados con los respectivos bloques de esfuerzos equivalentes del ACI y las NTCC-96, la zona de flexocompresión es distinta, debido a que el bloque propuesto por las NTCC-96 da origen a fuerzas de compresión y momentos flexionantes menores que la del bloque del ACI, y esto necesariamente redunda en una carga axial menor cuando se busca el equilibrio de fuerzas en la construcción de un diagrama de interacción. Por otro lado, se observa también que los valores calculados para flexión pura y para flexotensión son sensiblemente iguales.

Para observar el efecto que tiene el incremento de la resistencia a compresión del concreto en el bloque de esfuerzos, se hizo variar el valor de $f^{\prime}{ }_{c}$ de $250 \mathrm{~kg} / \mathrm{cm}^{2}$ a $400 \mathrm{~kg} / \mathrm{cm}^{2}$ construyendo diagramas de interacción normalizados respecto a la carga axial y momento máximos del ACI (figs. 2 y 3 ). En dichos diagramas se observa que, conforme aumenta el valor de $\mathrm{f}^{\prime}$, la diferencia entre el ACI y las NTCC-96 en la zona de flexocompresión aumenta hasta en más de 20\%, y que esta diferencia es mayor en los casos en que se utilizó el porcentaje mínimo de acero de refuerzo, debido a que la contribución del acero de refuerzo es menor. La variación de la proporción del momento máximo de las NTCC-96 respecto al del ACI con el incremento de $\mathrm{f}^{\mathrm{c}} \mathrm{c}$ es menos significativa.

Otra diferencia de las NTCC-96 es utilizar $\mathrm{f}_{\mathrm{c}}^{*}$ en lugar del $\mathrm{f}{ }_{\mathrm{c}}$; justificándose de la siguiente manera: "El valor nominal, $\mathrm{f}^{*}$, representa una resistencia tal que la probabilidad de que la resistencia del concreto en la estructura sea menor que $\mathrm{f}^{*}{ }_{\mathrm{c}}$ es aproximadamente de dos por ciento. El percentil dos corresponde al planteamiento general de los niveles de seguridad adoptados en el Reglamento del Distrito Federal. Por otra parte, en $\mathrm{f}^{*}{ }_{\mathrm{c}}$ está incluida la tendencia observada en el sentido de que la resistencia del concreto en la estructura es menor que la obtenida en los cilindros de control. Esta disminución es un efecto normal de las operaciones de colocación (transporte, hasta los moldes, compactación, etc.), así como de la menor eficacia que normalmente tiene el curado del concreto en la estructura con relación al curado de los cilindros"(“Comentarios", 1991).

Pudiera pensarse que las diferencias entre los resultados de aplicar las NTCC-96 y el ACI principalmente se deberían a la reducción de $\mathrm{f}^{\prime}{ }_{\mathrm{c}}$ que hacen las NTCC-96 al emplear $\mathrm{f}^{*}$, en las figs. 2 y 3 se muestran también diagramas de interacción donde no se considera el efecto de $\mathrm{f}^{*}$, $\mathrm{y}$ se advierte que esta observación es correcta en tanto no se incremente el valor de $\mathrm{f}$ 'c por los motivos que se comentan a continuación; si consideramos las ecuaciones de las NTCC-96 sin tomar en cuenta la reducción de $\mathrm{f}_{\mathrm{c}}$ que se hace al utilizar $\mathrm{f}_{\mathrm{c}}{ }_{\mathrm{c}}$ tendrían la siguiente forma:

$$
\begin{gathered}
\mathrm{k}_{1}=0.8 \\
\mathrm{k}_{3}=0.85 \mathrm{f}_{\mathrm{c}}^{\prime} \text { si } \quad \mathrm{f}^{\prime}{ }_{\mathrm{c}} \leq 250 \mathrm{~kg} / \mathrm{cm}^{2} \\
\mathrm{k}_{3}=\left(1.05-\frac{\mathrm{f}^{\prime}{ }_{\mathrm{c}}}{1250}\right) \text { si } \mathrm{f}^{\prime}{ }_{\mathrm{c}}>250 \mathrm{~kg} / \mathrm{cm}^{2}
\end{gathered}
$$


Observaciones sobre algunos criterios de diseño sísmico de edificios con marcos de concreto reforzado
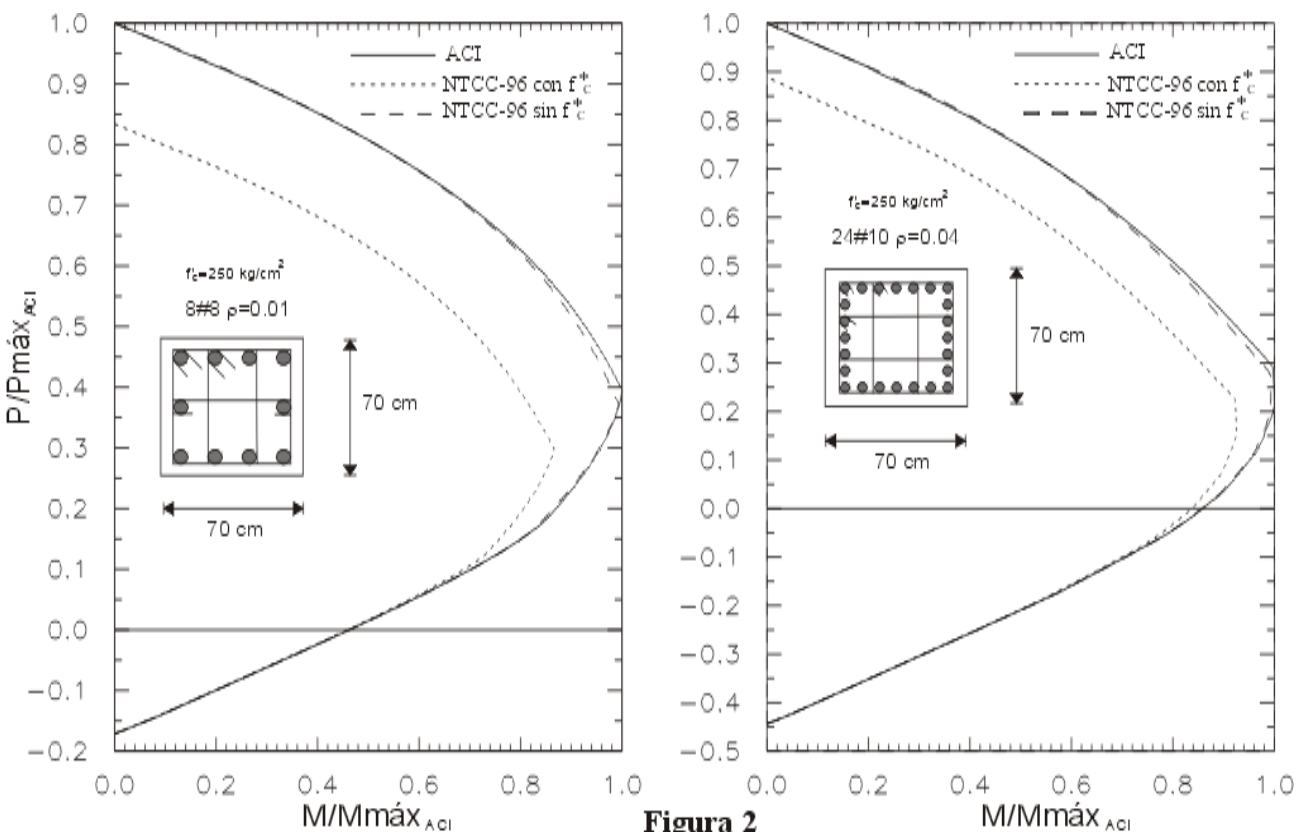

Figura 2. Comparación de diagramas de interacción obtenidos con bloques de esfuerzos del ACI y las NTCC para $\mathrm{f}^{\prime}{ }_{\mathrm{c}}=250 \mathrm{~kg} / \mathrm{cm}^{2}$, considerando y sin considerar $\mathrm{f}^{*} \mathrm{c}$.
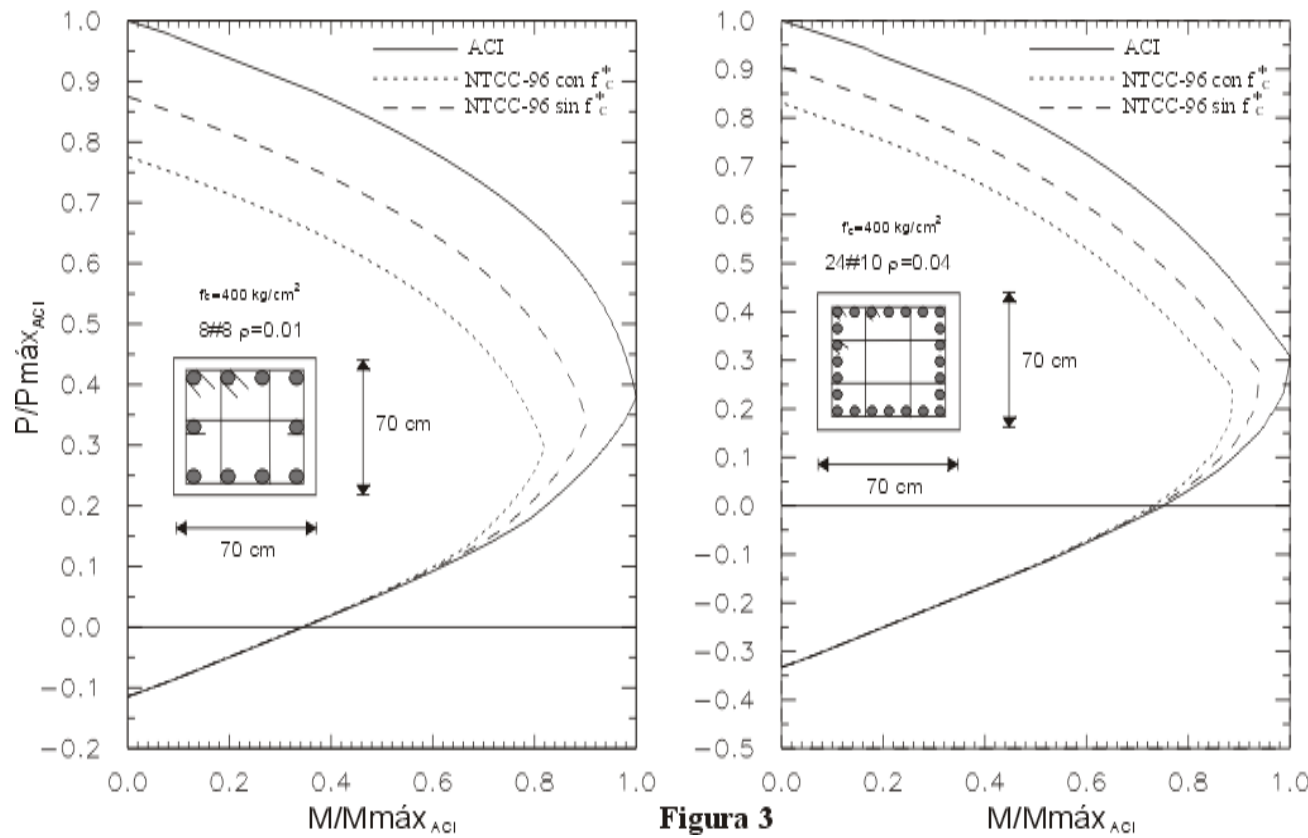

Figura 3. Comparación de diagramas de interacción obtenidos con bloques de esfuerzos del ACI y las NTCC para $\mathrm{f}^{\prime}{ }_{\mathrm{c}}=400 \mathrm{~kg} / \mathrm{cm}^{2}$, considerando y $\sin$ considerar $\mathrm{f}^{*} \mathrm{c}$.

Así, al calcular los respectivos valores de los parámetros $\mathrm{k}_{1} \mathrm{y} \mathrm{k}_{3}$, y de la fuerza de compresión del bloque equivalente asumiendo diferentes valores de $\mathrm{f}{ }_{\mathrm{c}}$ tendríamos tanto para las NTCC-96 como para el ACI lo siguiente: 


\begin{tabular}{|c|c|c|c|c|c|c|}
\hline & \multicolumn{3}{|c|}{ NTCC-96 sin $\mathrm{f}^{*}{ }_{\mathrm{c}}$} & \multicolumn{3}{c|}{ ACI } \\
\hline $\mathrm{f}^{\prime}{ }_{\mathrm{c}}\left(\mathrm{kg} / \mathrm{cm}^{2}\right)$ & $\mathrm{k}_{1}$ & $\mathrm{k}_{3}$ & $\mathrm{C}(\mathrm{kg})$ & $\mathrm{k}_{1}$ & $\mathrm{k}_{3}$ & $\mathrm{C}(\mathrm{kg})$ \\
\hline 250 & 0.8 & 0.85 & $170 \mathrm{bc}$ & 0.85 & 0.85 & $180.6 \mathrm{bc}$ \\
\hline 400 & 0.8 & 0.73 & $233.6 \mathrm{bc}$ & 0.76 & 0.85 & $259.9 \mathrm{bc}$ \\
\hline
\end{tabular}

Se aprecia que aún y cuando se ignora la reducción de $\mathrm{f}_{\mathrm{c}}$ que hacen las NTCC-96, los valores de las fuerzas de compresión y por consiguiente, de momentos flexionantes, son menores que los calculados con el bloque del ACI, redundando en cargas axiales menores cuando se establece el equilibrio de fuerzas internas y externas en la construcción del diagrama de interacción.

En la fig. 4 se comparan los parámetros $\mathrm{k}_{1} \mathrm{y} \mathrm{k}_{3}$ que definen las propiedades del bloque rectangular equivalente para cada reglamento, y donde se puede observar lo siguiente:

a) Para el parámetro $\mathrm{k}_{3}$ todos los reglamentos coinciden al proponer un valor constante, excepto las NTCC-96 que, como se mencionó anteriormente, varían el esfuerzo medio del bloque en lugar de su profundidad.

b) Para el parámetro $\mathrm{k}_{1}$ el ACI y UBC son sensiblemente iguales al NZS y CAN, existiendo una leve diferencia debida al manejo de unidades. En este caso las NTCC-96 establecen un valor constante de $\mathrm{k}_{1}$ (brazo de palanca constante).

c) Observando ambas gráficas, se pueden intuir valores más conservadores en las NTCC-96 para el cálculo de fuerzas a compresión y momentos flexionantes, lo que se comprueba cabalmente en las figs. 2 y 3.

El ACI establece un límite para el valor de $\beta_{1}\left(\mathrm{k}_{1}\right)$. En el suplemento al ACI 318-71 publicado en 1976, se adoptó un límite inferior de $\beta_{1}$ igual a 0.65 para resistencias de concreto mayores de $560 \mathrm{~kg} / \mathrm{cm}^{2}$ (fig. 4). Los datos obtenidos en pruebas de concreto de alta resistencia respaldaron el bloque de esfuerzos rectangular equivalente, para resistencias de concreto que excedan los $560 \mathrm{~kg} / \mathrm{cm}^{2}$, con un $\beta_{1}$ igual a 0.65 . El uso de la distribución rectangular equivalente especificada en el ACI 318-71 sin límite inferior en $\beta_{1}$ tuvo como resultado diseños incongruentes para concreto de alta resistencia para elementos sujetos a cargas axiales y de flexión combinadas (ACI-95, 1997). Las NTCC-96 no establecen ningún límite en el valor de $\mathrm{k}_{3}$, que es el valor que varía respecto al incremento en la resistencia a compresión (fig. 4).

En virtud de lo anteriormente expuesto, y de la observación que el bloque equivalente de esfuerzos no era congruente para el diseño de concretos de alta resistencia, en la propuesta para las NTCC-2001 existe una modificación mayor con respecto al bloque equivalente de esfuerzos que venían adoptando las NTCC-96 y versiones anteriores. En ella, al igual que los reglamentos ACI, UBC, CAN y NZS, se especifica un bloque de esfuerzos con una resistencia uniforme $\mathrm{f}^{\prime \prime}=0.85 \mathrm{f}^{*}{ }_{\mathrm{c}}$, es decir, $\mathrm{k}_{3}=0.85(0.8)=0.68$, mientras que el parámetro $\mathrm{k}_{1}\left(\beta_{1}\right)$ es ahora el que decrece linealmente de 0.85 a partir de $\mathrm{f}^{*}{ }_{\mathrm{c}}>280 \mathrm{~kg} / \mathrm{cm}^{2}$. Las NTCC-2001 establecen los siguientes límites en el valor de $\mathrm{f}^{\prime}{ }_{\mathrm{c}}$ para los concretos de alta resistencia: (1) $\mathrm{f}^{{ }_{\mathrm{c}}}=550 \mathrm{~kg} / \mathrm{cm}^{2}$ para estructuras diseñadas con un factor de comportamiento sísmico $\mathrm{Q}=4$ o en estructuras con miembros a flexocompresión que formen parte de marcos que resistan más del $50 \%$ de las 
acciones sísmicas y cuya carga axial de diseño exceda el $20 \%$ de la carga axial resistente de diseño $\mathrm{y},(2) \mathrm{f}^{\prime}{ }_{\mathrm{c}}=700 \mathrm{~kg} / \mathrm{cm}^{2}$ para todos los demás casos no incluidos en el inciso 1 anterior.
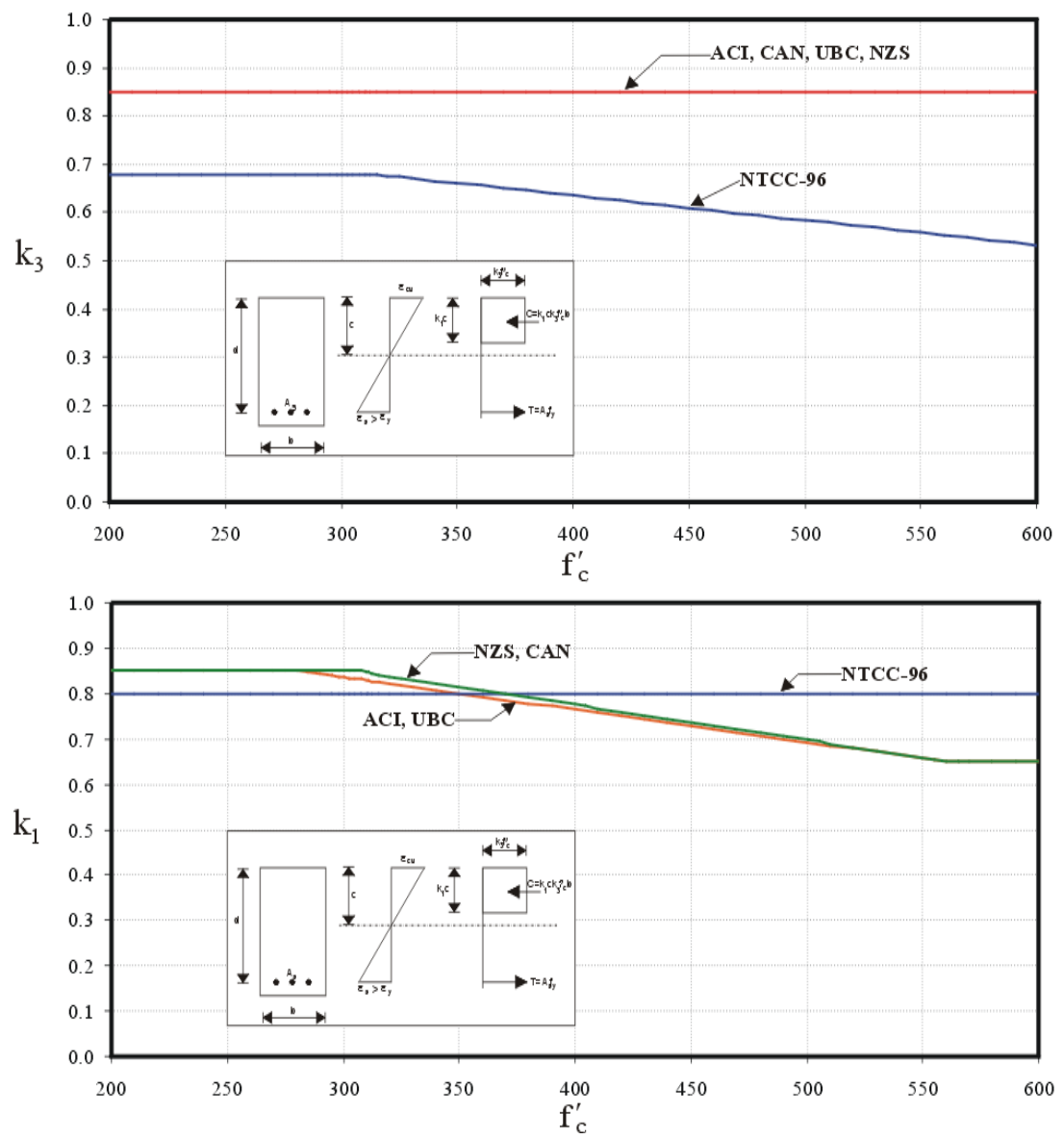

Figura 4. Comparación de los parámetros $\mathrm{k}_{1}$ y $\mathrm{k}_{3}$ que definen las propiedades del bloque rectangular equivalente de esfuerzos a compresión.

\section{ESPECIFICACIONES GENERALES PARA MARCOS NO DÚCTILES}

\section{Miembros a flexión}

\section{Factor de reducción de resistencia}

Los valores de los factores de reducción de resistencia para el caso de flexión se presentan en la tabla 2 y se observa que todos los reglamentos consideran el mismo valor de 0.9. El reglamento canadiense incorpora factores de reducción de resistencia que dependen del material y no de las acciones a las que estén sometidos los elementos, tales factores se definen de la siguiente forma: 
- $\varphi_{\mathrm{c}}=0.60$ para concreto.

- $\varphi_{\mathrm{s}}=0.85$ para acero.

El AIJ define esfuerzos permisibles para el concreto y el acero, y los incorpora en sus formulaciones.

\section{Refuerzo mínimo}

En la tabla 2 se muestran las áreas de acero mínimas propuestas por cada reglamento y se observa que las expresiones son muy similares, en todos los reglamentos se establece que no es necesario aplicar la fórmula de área mínima de acero si el área de refuerzo a tensión proporcionada es por lo menos un tercio mayor que la requerida por el análisis. Cabe hacer notar que las expresiones de la tabla 2 referentes a refuerzo mínimo en tensión se uniformizaron respecto a las unidades y a la definición de área de acero mínimo, ya que, por ejemplo, en el NZS se propone la expresión $\rho_{\text {mín }}=1.4 / f_{y}$, donde $f_{y}$ está en MPa y $\rho_{\text {mín }}=A_{\text {mín }} /$ bd es el porcentaje de acero de refuerzo mínimo a tensión. El criterio de las NTCC-96 se mantiene en las NTCC-2001.

\section{Refuerzo máximo}

En la tabla 2 se presentan las consideraciones de los reglamentos estudiados para limitar el porcentaje de refuerzo máximo en elementos a flexión las cuales coinciden en todos ellos.

El ACI establece que la limitación del $0.75 \rho_{\mathrm{b}}$ proporcionará el comportamiento dúctil necesario para la mayoría de los diseños, a menos que se requieran cantidades no usuales de ductilidad. De la misma forma, comenta que para el comportamiento de las vigas con refuerzo de compresión, únicamente deberá limitarse aquella porción de la totalidad del acero en tensión balanceada por la compresión en el concreto; la otra porción de la totalidad del acero en tensión en la cual la fuerza está balanceada por el refuerzo en compresión no necesita estar limitada por el factor de 0.75 (ACI-95, 1997).

Las NTCC-96 sugieren que el área máxima de acero de tensión en secciones de concreto reforzado que no deban resistir fuerzas sísmicas será la que corresponde a la falla balanceada de la sección considerada y en elementos a flexión que formen parte de sistemas que deban resistir fuerzas sísmicas, el área máxima de acero de tensión será 75 por ciento de la correspondiente a la falla balanceada. En las NTCC-2001 no hay cambio en cuanto al área máxima de acero en tensión en elementos que deban resistir fuerzas sísmicas; sin embargo, ahora limitan al $90 \%$ de la correspondiente a la falla balanceada para elementos que no deban resistir cargas sísmicas.

\section{Requisitos para refuerzo transversal}

El ACI establece que el refuerzo de compresión en vigas debe estar confinado para evitar el pandeo, utilizando estribos que satisfagan las limitaciones de tamaño y espaciamiento propuestos 
Observaciones sobre algunos criterios de diseño sísmico de edificios con marcos de concreto reforzado

para el caso de columnas; el UBC, CAN y el NZS proponen los mismos valores, las NTCC-96 no proponen ninguna limitación para esta condición.

\begin{tabular}{|c|c|c|c|c|c|c|}
\hline \multicolumn{7}{|c|}{ F L E X I ÓN } \\
\hline & ACI UBC & CAN & \multicolumn{2}{|c|}{ NZS } & NTCC-96 & AIJ \\
\hline$\phi \circ \mathrm{F}_{\mathrm{R}}$ & 0.90 & - & \multicolumn{2}{|c|}{0.90} & 0.90 & - \\
\hline$A_{\text {smín }}$ & $\begin{array}{c}\frac{0.8 \sqrt{\mathrm{f}^{\prime}}}{\mathrm{f}_{\mathrm{y}}} \mathrm{b}_{\mathrm{w}} \mathrm{d} \\
\mathrm{A}_{\mathrm{s} \min }>14.5 \frac{\mathrm{b}_{\mathrm{w}} \mathrm{d}}{\mathrm{f}_{\mathrm{y}}}\end{array}$ & $\begin{array}{c}\frac{0.8 \sqrt{\mathrm{f}^{\prime}{ }_{\mathrm{c}}}}{\mathrm{f}_{\mathrm{y}}} \mathrm{b}_{\mathrm{w}} \mathrm{d} \\
\mathrm{A}_{\mathrm{s} \min }>14.5 \frac{\mathrm{b}_{\mathrm{w}} \mathrm{d}}{\mathrm{f}_{\mathrm{y}}}\end{array}$ & \multicolumn{2}{|c|}{$\frac{14.28 b_{w} d}{f_{y}}$} & $\frac{0.7 \sqrt{f^{\prime}}}{f_{y}}$ bd & $0.004 \mathrm{bd}$ \\
\hline$\rho_{\text {máx }}$ & $\leq 0.75 \rho_{\mathrm{b}}$ & $\leq 0.75 \rho_{\mathrm{b}}$ & \multicolumn{2}{|c|}{$\leq 0.75 \rho_{\mathrm{b}}$} & $\begin{array}{l}\leq \rho_{\mathrm{b}} \text { No sísmico. } \\
\leq 0.75 \rho_{\mathrm{b}} \text { Sísmico. }\end{array}$ & - \\
\hline \multicolumn{7}{|c|}{ F LEX OCOMPRESIÓN Y F LEXOTEN S Í N } \\
\hline & ACI UBC & CAN & \multicolumn{2}{|c|}{ NZS } & NTCC-96 & AIJ \\
\hline$\phi \circ F_{R}$ & 0.70 a 0.90 & - & \multicolumn{2}{|c|}{0.70 a 0.90} & 0.70 y 0.80 & - \\
\hline \multirow[b]{2}{*}{$\mathbf{s}<$} & $16 \phi_{1}$ & $16 \phi_{1}$ & $\phi=0.9$ & $\phi=0.7$ & $\sqrt{\mathrm{f}_{\mathrm{y}}} \phi_{1}$ & \multirow[b]{2}{*}{ - } \\
\hline & $48 \phi_{\mathrm{e}}$ & $48 \phi_{\mathrm{e}}$ & $\begin{array}{l}16 \phi_{1} \\
20 \mathrm{~cm}\end{array}$ & $\begin{array}{c}48 \phi_{\mathrm{e}} \\
\mathrm{b}\end{array}$ & $\begin{array}{l}48 \phi_{\mathrm{e}} \\
\frac{1}{2} \mathrm{~b}\end{array}$ & \\
\hline$\rho_{\text {mín }}$ & 0.01 & 0.01 & \multicolumn{2}{|c|}{0.008} & $\frac{20}{f_{y}}$ & 0.008 \\
\hline$\rho_{\text {máx }}$ & 0.08 & 0.08 & \multicolumn{2}{|c|}{0.08} & 0.06 & - \\
\hline \multicolumn{7}{|c|}{ 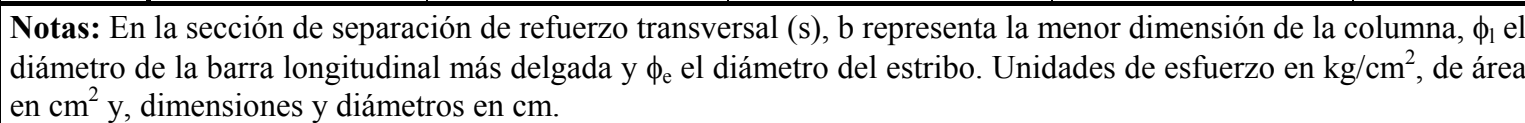 } \\
\hline
\end{tabular}

\section{Miembros a flexocompresión}

\section{Factor de reducción de resistencia}

Los valores de los factores de reducción de resistencia para el caso de flexocompresión se presentan en la tabla 2. Si los elementos sometidos a flexión y carga axial cumplen con los requerimientos de refuerzo transversal más estrictos, los reglamentos asignan un valor mayor para el factor de reducción de resistencia, de lo contrario se asigna el valor mínimo. El ACI, UBC y NZS contemplan el caso en que el elemento esté sujeto a cargas axiales pequeñas y varían 
linealmente el factor de reducción de resistencia respecto a dicha carga axial, entre más pequeña es la carga axial, mayor es el factor de reducción de resistencia:

a) Tensión axial y tensión axial con flexión

b) Compresión axial y flexocompresión axial:

Elementos con refuerzo en espiral

Otros elementos reforzados 0.70

Excepto que para valores bajos de compresión axial, $\phi$ se puede incrementar de acuerdo con lo siguiente:

Para elementos en los cuales $\mathrm{f}_{\mathrm{y}}$ no exceda de $4200 \mathrm{~kg} / \mathrm{cm}^{2}$, con acero de refuerzo simétrico, $\phi$ se puede aumentar linealmente hasta 0.90 , en tanto que $\phi \mathrm{P}_{\mathrm{n}}$ disminuye de $0.10 \mathrm{f}_{\mathrm{c}}{ }_{\mathrm{c}} \mathrm{A}_{\mathrm{g}}$, a cero. Para otros elementos con acero de refuerzo, $\phi$ se puede incrementar linealmente hasta 0.90 en tanto $\phi \mathrm{P}_{\mathrm{n}}$ disminuye de $0.10 \mathrm{f}_{\mathrm{c}}{ }_{\mathrm{c}} \mathrm{A}_{\mathrm{g}} \phi \mathrm{P}_{\mathrm{b}}$, según el que sea menor, a cero (ACI-95, 1997).

Por otro lado, las NTCC-96 establecen que, en flexocompresión $\mathrm{F}_{\mathrm{R}}$ se tomará igual a 0.8 cuando el núcleo esté confinado con un zuncho o con estribos, y también cuando el elemento falle en tensión. Si el núcleo no está confinado y la falla es en compresión, $\mathrm{F}_{\mathrm{R}}$ se supondrá igual a 0.7. Para aplastamiento $F_{R}$ valdrá 0.7 (NTCC-96, 1996). Este criterio se mantiene en la propuesta de las NTCC-2001.

\section{Geometría}

Las NTCC-96 y la propuesta de NTCC-2001 estipulan que la relación entre la dimensión transversal mayor de una columna y la menor no excederá de cuatro, y que la dimensión transversal menor será por lo menos igual a $20 \mathrm{~cm}$ (NTCC-96, 1996). Los demás códigos no presentan una restricción explícita en este sentido.

\section{Refuerzo máximo}

En la tabla 2 se muestra la relación máxima entre el área de acero de refuerzo y el área total de la sección planteada por cada reglamento. Las NTCC-96 y la propuesta de NTCC-2001 sugieren la relación menor de las máximas de todos los reglamentos 0.06 , en los otros códigos el valor de 0.08 coincide.

\section{Refuerzo mínimo}

En la tabla 2 se muestra la relación mínima entre el área de acero de refuerzo y el área total de la sección planteada por cada reglamento. Las NTCC-96 y la propuesta de NTCC-2001 sugieren la relación menor de todos los reglamentos ya que si se sustituye el valor de $f_{y}=4200 \mathrm{~kg} / \mathrm{cm}^{2}$ en la 
expresión la relación resulta ser 0.005 , pero resulta interesante que se haga variar respecto al esfuerzo de fluencia del acero y no que se establezca un valor fijo como en los otros reglamentos.

En todos los reglamentos se sugiere que el número mínimo de varillas sea seis en columnas circulares y cuatro en rectangulares. El ACI establece que para otras formas, debe proporcionarse una varilla en cada vértice o esquina y aplicarse refuerzo lateral apropiado.

\section{Requisitos para refuerzo transversal}

Todas las columnas deben cumplir con los requisitos mínimos siguientes planteados por los reglamentos, pero además el refuerzo transversal no será menor que el necesario por resistencia a fuerza cortante y torsión. La separación máxima de estribos de refuerzo para elementos sujetos a compresión se compara en la tabla 2, la intención de reducir la separación de estribos es de proveer de cierta ductilidad a las columnas. Como se observa, el reglamento neozelandés es el que propone los valores más severos.

En el NZS se establecen diferentes factores de reducción de resistencia $(\phi)$ para miembros que soportan carga axial con o sin flexión, si dichos miembros cumplen con los requerimientos de refuerzo transversal más estrictos se especifica un valor de $\phi=0.9$, de no ser así, se establece $\phi=0.7$, permitiendo requerimientos de refuerzo transversal menos rigurosos. Se propone el valor del área de estribos, el cual no debe ser menor de $A_{s h}=0.3 \mathrm{~s}_{h} h^{\prime \prime}\left(\frac{A_{g}}{A_{c}}-1\right) \frac{f_{c}^{\prime}}{f_{h}}$ para $\phi=0.9$; en el caso de $\phi=0.7$ el valor de $A_{\text {sh }}$ puede ser menor al presentado en la ecuación anterior.

Las columnas con una gran cantidad de refuerzo transversal confinante muestran una ductilidad significativa ante grandes deformaciones axiales, después de la carga última, cuando se ha perdido el recubrimiento. Esta ductilidad está asociada al incremento de esfuerzo y de ductilidad en el núcleo de concreto, y a la restricción en contra del pandeo del refuerzo longitudinal, provisto por el refuerzo transversal confinante (NZS-82, 1982).

El ACI, UBC, NZS y CAN establecen que todas las varillas deben estar confinadas por medio de estribos laterales del \#3, por lo menos, para varillas longitudinales del \#10 o menores; del \#4, como mínimo, para varillas longitudinales del \#11, 14 y 18 y paquetes longitudinales de varillas.

En todos los reglamentos se estipula que los estribos se deben disponer, de tal forma, que cada varilla de esquina y varilla alternada longitudinal tenga apoyo lateral proporcionado por el doblez de un estribo con un ángulo no mayor a $135^{\circ}$, y ninguna varilla debe estar separada más de $15 \mathrm{~cm}$ libres en cada lado a lo largo del estribo, desde la varilla lateralmente soportada (ACI95, 1997).

De la misma forma, se define que en la parte de la columna situada por encima del nivel superior de las losas de entrepiso o zapatas, los estribos se deben disponer verticalmente a no más de la mitad del espaciamiento entre estribos en el resto de la columna; y en la parte inferior de la 
columna situada por debajo del refuerzo horizontal más bajo de la losa o ábaco que soporta, se deben espaciar los estribos a no más de la mitad del espaciamiento entre estribos (ACI-95, 1997). La intención de reducir la separación de los estribos cerca de los nudos es aumentar la ductilidad de la columna en esas zonas, que son críticas bajo cargas sísmicas.

El AIJ establece que, para estribos del \#3, la separación en la zona cercana a nudos no debe exceder de $10 \mathrm{~cm}$ y que el espaciamiento puede aumentarse a $15 \mathrm{~cm}$ en el resto de la columna. Si se utiliza un diámetro mayor de estribos se puede a aumentar apropiadamente la separación a $20 \mathrm{~cm}$.

Las NTCC-96 y la propuesta de NTCC-2001 limitan la distancia en la que se disminuirá a la mitad la separación de estribos y se indica que dicha longitud no sea menor que la dimensión transversal máxima de la columna, un sexto de su altura libre, ni que $60 \mathrm{~cm}$, arriba y debajo de cada unión de columna con trabes o losas, medida a partir del respectivo plano de intersección (NTCC-96, 1996).

\section{Fuerza Cortante}

La mayoría de los reglamentos proponen que la resistencia nominal al cortante, $\mathrm{V}_{\mathrm{n}}$, se calcule mediante la expresión:

$V_{n}=V_{c}+V_{s}$

donde $\mathrm{V}_{\mathrm{c}}$ es la resistencia nominal al cortante proporcionada por el concreto y $\mathrm{V}_{\mathrm{s}}$ es la resistencia nominal al cortante proporcionada por el acero de refuerzo para cortante. A continuación se presenta una comparación entre las expresiones propuestas por cada reglamento para tales resistencias.

\section{Factor de reducción de resistencia}

Los valores de los factores de reducción de resistencia para cortante coinciden para el ACI, UBC y NZS con un valor de 0.85 , las NTCC-96 y la propuesta de NTCC-2001 consideran un valor de 0.8 .

\section{Resistencia al cortante proporcionada por el concreto}

El ACI propone dos opciones para evaluar la fuerza cortante que toma el concreto. Las ecuaciones (a) y (b) de la tabla 3, para vigas y columnas respectivamente, corresponden al método más sencillo; para elementos sujetos a tensión axial significativa, el refuerzo por cortante se debe diseñar para que resista el cortante total, a menos que se haga un análisis más detallado utilizando la ecuación (f). 
Observaciones sobre algunos criterios de diseño sísmico de edificios con marcos de concreto reforzado

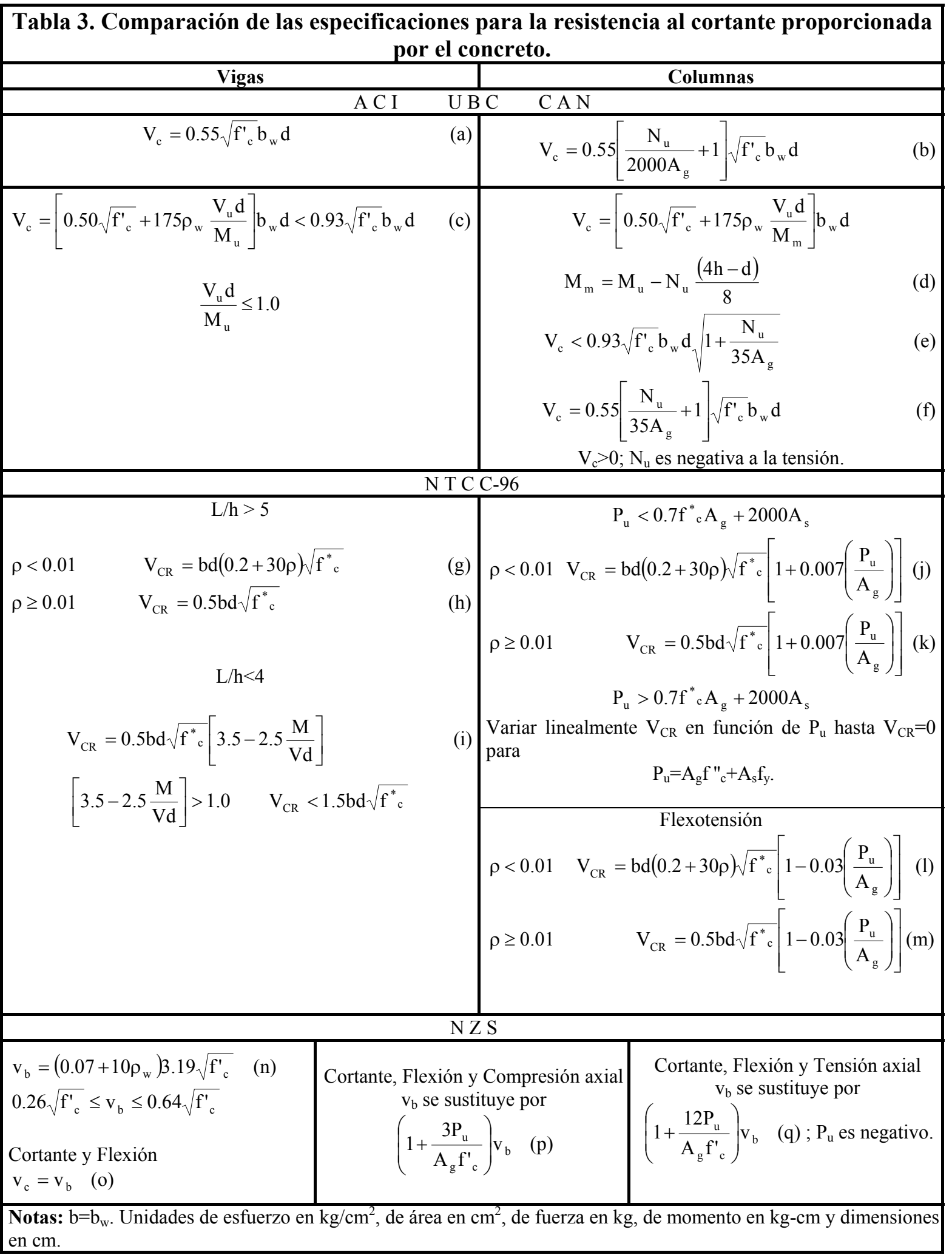


La ecuación (c) de la tabla 3 es la expresión básica para la resistencia al cortante de elementos sin refuerzo por cortante. Se debe tener en cuenta que las tres variables de la ecuación (c), $\sqrt{\mathrm{f}^{\prime}{ }_{\mathrm{c}}}$ (como medida de la resistencia a tensión del concreto), $\rho_{\mathrm{w}}, \mathrm{y} \mathrm{V}_{\mathrm{u}} \mathrm{d} / \mathrm{M}_{\mathrm{u}}$ afectan la resistencia al cortante, aunque algunos datos de investigación indican que la ecuación (c) sobrestima la influencia de $\mathrm{f}_{\mathrm{c}}$ y subestima la influencia de $\rho_{\mathrm{w}} \mathrm{y} \mathrm{V}_{\mathrm{u}} \mathrm{d} / \mathrm{M}_{\mathrm{u}}$ (ACI-95, 1997). La información adicional indica que la resistencia al cortante disminuye a medida que aumenta el peralte total del elemento. El valor mínimo de $\mathrm{M}_{\mathrm{u}}$ igual a $\mathrm{V}_{\mathrm{u}} \mathrm{d}$ en la ecuación (c) sirve para limitar $\mathrm{V}_{\mathrm{c}}$ cerca de los puntos de inflexión. Para la mayoría de los diseños es conveniente suponer que el segundo término de la ecuación (c) es igual a $0.03 \sqrt{\mathrm{f}^{\prime}{ }_{\mathrm{c}}}$ y utilizar $\mathrm{V}_{\mathrm{c}}=0.53 \sqrt{\mathrm{f}_{\mathrm{c}} \mathrm{b}_{\mathrm{w}}} \mathrm{d}$ conforme a la ecuación (a) (ACI-95, 1997).

Las ecuaciones (d) y (e) de la tabla 3, para elementos sujetos a compresión axial, además de cortante y flexión, se han derivado del informe del Comité ACI-ASCE 326. A medida que $\mathrm{N}_{\mathrm{u}}$ aumenta, el valor de $\mathrm{V}_{\mathrm{c}}$ calculado por medio de las ecuaciones (c) y (d) excederá el límite superior obtenido por la ecuación (e) antes de que llegue a ser negativo el valor de $\mathrm{M}_{\mathrm{m}}$ dado por la ecuación (d). El valor de $\mathrm{V}_{\mathrm{c}}$ obtenido con la ecuación (c) no tiene ninguna interpretación física si se sustituye un valor negativo de $\mathrm{M}_{\mathrm{m}}$. Para esta condición deben utilizarse las ecuaciones (e) o (b) para calcular $\mathrm{V}_{\mathrm{c}}$. Debido a la complejidad en la utilización de las ecuaciones (c) y (d), se permite una disposición alternativa de diseño, la ecuación (b) de la misma tabla (ACI-95, 1997).

La ecuación (f) de la tabla 3 puede utilizarse para calcular $V_{c}$ en elementos sujetos a tensión axial significativa. El refuerzo por cortante puede entonces diseñarse para $V_{n}-V_{c}$. Los bajos niveles de tensión axial ocurren a menudo debido a cambios de volumen, pero no son importantes en estructuras con adecuadas juntas de expansión y con refuerzo mínimo. Puede ser deseable diseñar el refuerzo por cortante para resistir el cortante total, si hay incertidumbre acerca de la magnitud de la tensión axial (ACI-95, 1997).

Algunas diferencias se observan en el reglamento canadiense respecto al ACI en el cálculo de la fuerza cortante en columnas, utilizando expresiones muy parecidas a las del reglamento neozelandés (Habibullah, 1992). Para compresión axial:

$$
V_{c}=0.64 \varphi_{c}{\sqrt{f^{\prime}}}_{c}\left(1+\frac{3 P_{u}}{A_{g} f^{\prime}{ }_{c}}\right) b_{w} d
$$

para tensión axial $\mathrm{P}_{\mathrm{u}}$ es negativa $\mathrm{y}$ :

$V_{c}=0.64 \varphi_{c} \sqrt{f^{\prime}{ }_{c}}\left(1+\frac{3 P_{u}}{1.92 \varphi_{c} \sqrt{f^{\prime}{ }_{c} A_{g}}}\right) b_{w} d$

Las expresiones que se presentan en la tabla 3 correspondientes a las NTCC-96 son aplicables cuando la dimensión transversal, h, del elemento, paralela a la fuerza cortante, no es mayor que $70 \mathrm{~cm}$ y, además, la relación $\mathrm{h} / \mathrm{b}$ no excede de seis $(h / b \leq 6)$. Por cada una de las dos 
condiciones anteriores que no se cumpla, se reducirá $\mathrm{V}_{\mathrm{cR}}$ dado por dichas expresiones en 30 por ciento (NTCC-96, 1996). Las reducciones en $V_{\mathrm{cR}}$ tienen como antecedentes los ensayes sobre el efecto del tamaño de la sección. Los resultados de dichos ensayes indican que $\mathrm{V}_{\mathrm{cR}}$ disminuye al aumentar el tamaño y la relación peralte-ancho ("Comentarios", 1991). La propuesta de NTCC2001 introduce una corrección para cuando el peralte del elemento excede de $70 \mathrm{~cm}$. Para este caso, el valor de $\mathrm{V}_{\mathrm{CR}}$ se reduce linealmente a partir de un peralte $\mathrm{de} \mathrm{h}=70 \mathrm{~cm}$ de la siguiente manera:

$V_{C R}{ }^{\prime}=V_{C R}(1-0.004[h-70])$

En ningún caso el valor de $\mathrm{V}_{\mathrm{CR}}$ ' será inferior a $0.8 \mathrm{~V}_{\mathrm{CR}}$. Esta modificación se debe a que se consideraba insatisfactoria una reducción abrupta de la resistencia para peraltes mayores a 70 $\mathrm{cm}$, sobre todo si el peralte excedente era muy reducido en proporción (es decir, algunos centímetros de más).

En vigas con relación claro a peralte total, $\mathrm{L} / \mathrm{h}$, no menor que cinco $(L / h<5)$, la fuerza cortante que toma el concreto, $\mathrm{V}_{\mathrm{cR}}$, se calculará con las ecuaciones $(\mathrm{g})$ y $(\mathrm{h})$ de la tabla 3 según las NTCC-96. En la propuesta de NTCC-2001, el límite de $\rho$ cambia en las ecuaciones (g) y (h) de $\rho=0.01$ a $\rho=0.015$. En consecuencia, la ecuación $(\mathrm{g})$ se adapta y ahora es:

$V_{C R}=b d(0.2+20 \rho) \sqrt{f^{*}}$

$\mathrm{Si} \mathrm{L/h}$ es menor que cuatro $(L / h<4)$ y las cargas y reacciones comprimen directamente las caras superior e inferior de la viga, $\mathrm{V}_{\mathrm{cR}}$ se obtendrá mediante la ecuación (i) de la tabla, tanto para las NTCC-96 como para la propuesta de NTCC-2001. Si las cargas y reacciones no comprimen las caras superior e inferior de la viga, se aplicará la ecuación (h). Para relaciones $\mathrm{L} / \mathrm{h}$ comprendidas entre cuatro y cinco, $\mathrm{V}_{\mathrm{cR}}$ se hará variar linealmente hasta los valores dados por las ecuaciones (g) y (h) (NTCC-96, 1996). Estas últimas disposiciones se mantienen en lo general en las NTCC-2001.

Se ha demostrado en diversos estudios la necesidad de hacer depender la fuerza cortante que toma el concreto de la cuantía de acero longitudinal de tensión en forma más directa, este criterio ha sido adoptado también por reglamentos europeos. Lo que en una viga con refuerzo transversal se llama "contribución del concreto", $\mathrm{V}_{\mathrm{cR}}$, consta en realidad del componente vertical de la fuerza que actúa en el concreto arriba de la grieta, de la fricción que se genera en ésta entre las superficies de concreto en contacto, y de la fuerza cortante que toma el propio refuerzo longitudinal. Si disminuye la cuantía de refuerzo longitudinal, disminuye la fuerza cortante que toma dicho refuerzo y, por otra parte, la grieta diagonal se hace más larga y ancha, con lo que se reduce la capacidad de la zona de compresión y disminuye la fricción a lo largo de la grieta. El factor $(3.5-2.5 \mathrm{M} / \mathrm{Vd})$ toma en cuenta que las condiciones de equilibrio de una viga después del agrietamiento diagonal mejoran conforme disminuye la relación claro de cortante a peralte ("Comentarios", 1991). 
Las expresiones de las NTCC-96 correspondientes a miembros sujetos a flexión y carga axial se muestran en la tabla 3. De acuerdo con los comentarios de las NTCC-96 ("Comentarios", 1991) dichas expresiones están basadas en el Reglamento ACI 318-83 y sus comentarios ACI 318R-83, y toman en cuenta que la resistencia a tensión diagonal aumenta o disminuye según si el miembro está sujeto a compresiones o tensiones axiales.

A pesar de que los Comentarios de las NTCC-96 mencionan que sus formulaciones correspondientes a miembros sujetos a cortante, flexión y carga axial están basadas en el Reglamento ACI 318-83 y sus comentarios ACI 318R-83, resultaría evidente después de observar las expresiones de los reglamentos, reproducidas en la tabla 3, que las formulaciones de las NTCC-96 referentes a cortante provendrían más bien de las propuestas por el reglamento neozelandés (NZS), no solamente las que corresponden a flexión y compresión axial, sino aquellas relacionadas con flexión y flexotensión. Sin embargo, la semejanza que se observa se debe más bien a que el reglamento NZS se basa en este criterio en las recomendaciones del Comité ACI-ASCE 426 de 1973 ("Revisor”, 2001).

En la tabla 3 también se presentan las expresiones propuestas por el NZS para cortante, se establece la expresión básica de esfuerzo cortante que toma el concreto (ecuación n) y con ella se forman diferentes ecuaciones dependiendo de las condiciones de carga del elemento. En la ecuación (n) primero se determina el refuerzo longitudinal de flexión y posteriormente se verifica la capacidad a cortante tomando en cuenta los cortes que se hacen en el refuerzo a flexión. Sólo se deben tomar en cuenta las barras que tienen una longitud de desarrollo completa en el cálculo de $\rho_{\mathrm{w}}$. Por facilidad, $\mathrm{v}_{\mathrm{b}}$ se hizo independiente del valor $\mathrm{M} / \mathrm{Vd}$ que se utiliza en el ACI. El valor del esfuerzo cortante $\mathrm{v}_{\mathrm{c}}$ se incrementa cuando existe compresión axial, de la misma forma disminuye en la presencia de tensión axial, por eso el segundo término de la ecuación (q) siempre es negativo (NZS-82, 1982).

En la fig. 5 se hace una comparación gráfica de la variación de $\frac{V_{c}}{\sqrt{f^{\prime}{ }_{c} b_{w} d}}$ respecto a $\frac{V_{u} d}{M_{u}}$ contemplando, además, otros términos involucrados en las formulaciones de cortante para vigas mostradas en la tabla 3 .

El cortante que toma el concreto es afectado primordialmente por el esfuerzo en el concreto representado en las expresiones como $\sqrt{f^{\prime}{ }_{c}}$, por la relación de acero longitudinal $\rho_{\mathrm{w}} ; \mathrm{y}$ para claros de cortante $(\mathrm{L} / \mathrm{h})$ cortos por la relación de claro de cortante contra peralte $\frac{\mathrm{M}}{\mathrm{Vd}}(\mathrm{NZS}$ $82,1982)$.

En la gráfica de la fig. 5 correspondiente a los reglamentos ACI, UBC y CAN se observa que la variación de $\frac{V_{c}}{\sqrt{f^{\prime}{ }_{c} b_{w} d}}$ respecto a $\frac{V_{u} d}{M_{u}}$ depende, en la ecuación (c) del ACI, de f ${ }^{\prime}{ }_{c} y \rho_{w}, y$ que como se mencionó anteriormente, se permite un valor máximo de uno para la relación $\frac{V_{u} d}{M_{u}}, a$ fin de limitar $\mathrm{V}_{\mathrm{c}}$ cerca de los puntos de inflexión (en estos puntos $\mathrm{M}_{\mathrm{u}}$ es igual a cero o es muy 
pequeño); los valores propuestos de $\mathrm{f}^{\prime} \mathrm{c}$ en dicha gráfica de $200 \frac{\mathrm{kg}}{\mathrm{cm}^{2}}$ y $350 \frac{\mathrm{kg}}{\mathrm{cm}^{2}}$ corresponden a lo que se utiliza comúnmente en la práctica. En la gráfica relacionada con el NZS y las NTCC-96, la variación de $\frac{V_{c}}{\sqrt{f^{\prime}{ }_{c} b_{w} d}}$ respecto a $\frac{V_{u} d}{M_{u}}$ no depende de $f^{\prime}{ }_{c}$.
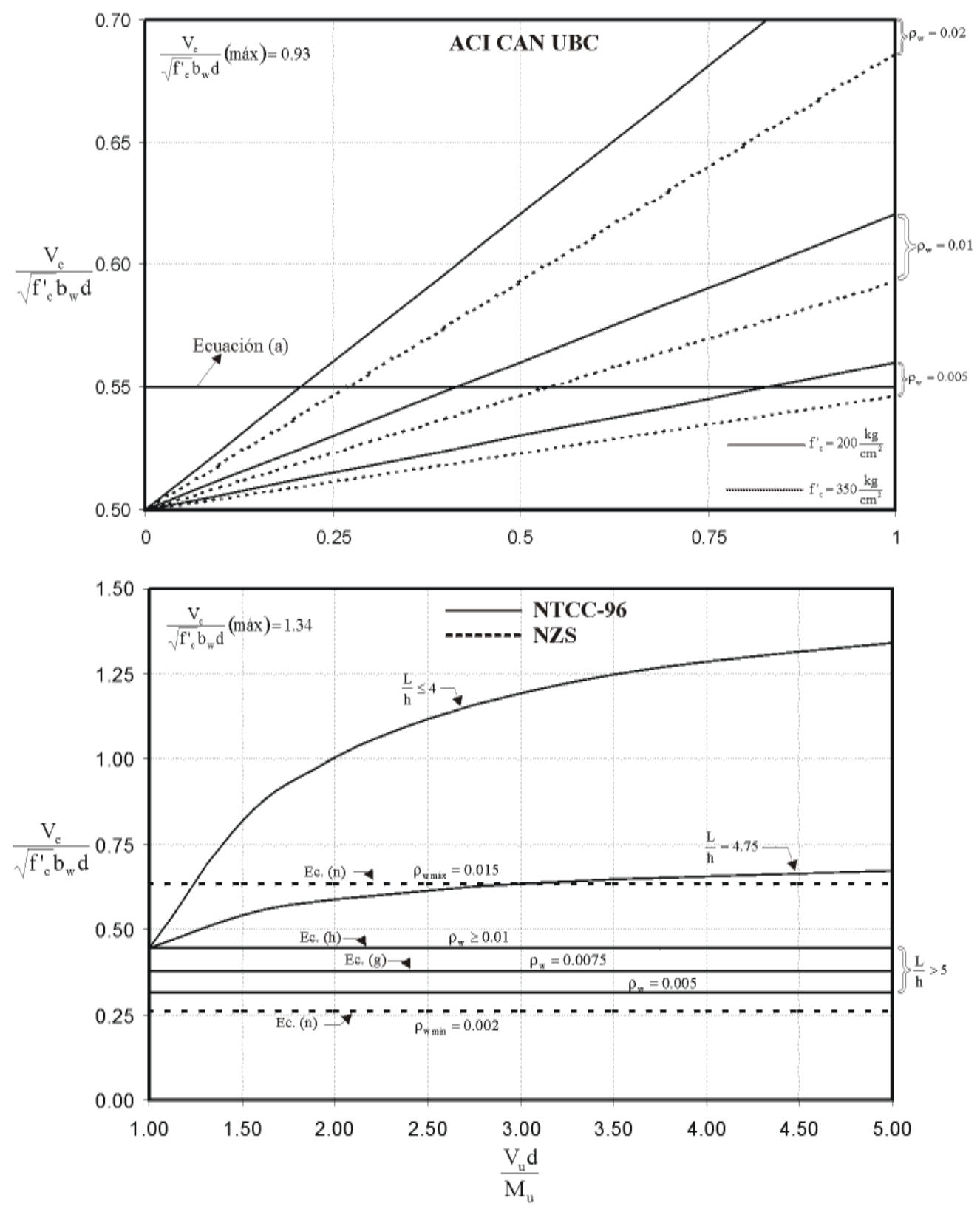

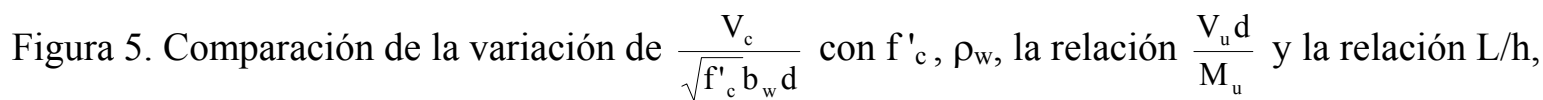
para vigas en los reglamentos estudiados. 
Sin embargo, la ecuación (c) del ACI (tabla 3) no limita la relación $\frac{\mathrm{V}_{\mathrm{u}} \mathrm{d}}{\mathrm{M}_{\mathrm{u}}}$ por el claro de cortante $(\mathrm{L} / \mathrm{h})$ como lo hacen las NTCC-96, que utilizan esta relación únicamente en claros pequeños, ya que no sólo es poco significativa para vigas con claros largos, sino que, además, una vez que se desarrolla el agrietamiento inclinado, se presenta cierta acción de arco en la viga $\mathrm{y}$, como consecuencia de esta acción, la distribución de esfuerzos de flexión no corresponde ya al diagrama de momentos flexionantes, por lo que el significado del término $\frac{V_{u} d}{M_{u}}$ pierde sentido (MacGregor y Gergely, 1977).

En las ecuaciones de las NTCC-96 se toman en cuenta todas las relaciones y términos que afectan al cortante que toma el concreto. Como se observa en la fig. 5, a diferencia del ACI, la relación $\frac{\mathrm{V}_{\mathrm{u}} \mathrm{d}}{\mathrm{M}_{\mathrm{u}}}$ debe ser mayor que uno, el factor $\left(3.5-2.5 \frac{\mathrm{M}}{\mathrm{Vd}}\right)$ toma en cuenta que las condiciones de equilibrio de una viga después del agrietamiento diagonal mejoran conforme disminuye la relación claro de cortante a peralte ("Comentarios", 1991). En el caso del NZS, se menciona que, por simplicidad, el esfuerzo cortante se hizo independiente del parámetro $\frac{\mathrm{M}}{\mathrm{Vd}}$ que se usa en el ACI y las NTCC-96, por lo que en la fig. 5 se observan constantes las curvas relacionadas con el NZS.

La fig. 6 es resultado de las gráficas mostradas en la fig. 5, igualmente se hace una comparación de la variación de $\frac{\mathrm{V}_{\mathrm{c}}}{\sqrt{\mathrm{f}_{\mathrm{c}}^{\prime} \mathrm{b}_{\mathrm{w}} \mathrm{d}}}$ respecto a $\frac{\mathrm{V}_{\mathrm{u}} \mathrm{d}}{\mathrm{M}_{\mathrm{u}}}$, pero manteniendo fijos los valores de $\mathrm{f}^{\prime}{ }_{\mathrm{c}}=200 \frac{\mathrm{kg}}{\mathrm{cm}^{2}}$ y $\rho_{\mathrm{w}}=0.01$, e involucrando a todos los reglamentos en una misma gráfica, a fin de evidenciar más sus diferencias y similitudes. En esta figura se hace aún más evidente que las expresiones de las NTCC-96 para $\frac{\mathrm{L}}{\mathrm{h}}>5$ están más relacionadas con el código neozelandés que con las del ACI, o en otras palabras, en el Comité ACI 426 de 1973.

La gráfica presentada en la fig. 7 para el ACI y UBC muestra los límites aproximados de los valores de $\mathrm{V}_{\mathrm{c}}$ para secciones sujetas a compresión axial, obtenidos a partir de las ecuaciones (c) y (d) de la tabla 3. Los valores corresponden a una viga de $15 \times 30 \mathrm{~cm}$ con un peralte efectivo de $27.4 \mathrm{~cm}$. También se indican las curvas correspondientes a las expresiones alternas para $\mathrm{V}_{\mathrm{c}}$ dadas por las ecuaciones (b) y (e) de la misma tabla, así como las correspondientes a la ecuación (f) para miembros sometidos a tensión axial (Ghosh et al., 1996).

De la misma manera, la gráfica para las NTCC-96, NZS y CAN mostrada en la fig. 7 presenta los límites de los valores de $\mathrm{V}_{\mathrm{c}}$ obtenidos a partir de las ecuaciones (q) y (p) de la tabla 3 para los códigos canadiense y neozelandés, y los límites obtenidos para las NTCC-96 mediante las ecuaciones $(\mathrm{m}) \mathrm{y}(\mathrm{k})$, para porcentajes de acero de refuerzo mayores o iguales a uno por ciento $(\rho \geq 0.01)$, así como los límites calculados con las ecuaciones (l) y (j) para porcentajes de acero de refuerzo menores. 


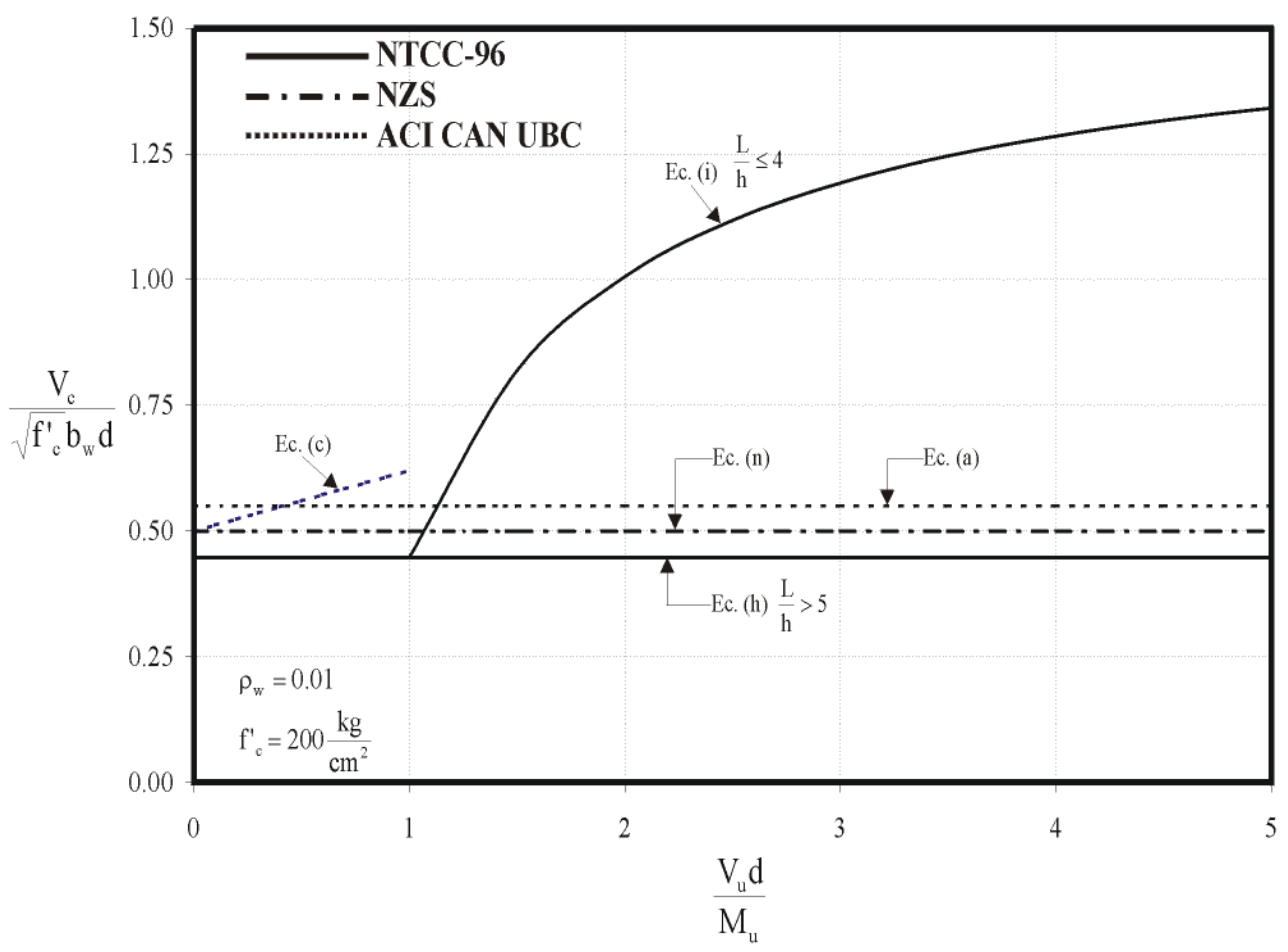

Figura 6. Comparación de la variación de $\frac{V_{c}}{\sqrt{f^{\prime}{ }_{c} b_{w} d}}$ con $\frac{V_{u} d}{M_{u}}$ manteniendo fijos los valores de $f^{\prime}{ }_{c}$ y $\rho_{\mathrm{w}}$ para vigas en los reglamentos estudiados.

Se observa en estas dos gráficas que, en el caso de flexotensión, el ACI presenta valores superiores a los de los códigos que toman en cuenta la variación respecto al porcentaje de acero de refuerzo, y dichos valores resultan ser poco conservadores respecto a los otros códigos para porcentajes de acero de refuerzo menores al $1.5 \%$.

En el caso de flexocompresión, los límites establecidos por el ACI resultan ser también mayores, aún y cuando las formulaciones para esta condición de carga si toman en cuenta el porcentaje de acero de refuerzo. El hecho de considerar la relación claro de cortante contra peralte incrementa los valores calculados, aunque como se ha venido mencionando, dicha relación es poco significativa en claros largos.

\section{Resistencia al cortante proporcionada por el acero de refuerzo}

Las especificaciones y las expresiones correspondientes al acero de refuerzo por cortante (tabla 4) son básicamente las mismas en todos los reglamentos, difiriendo entre ellos los factores de reducción por resistencia y, en el caso de las NTCC-96, la utilización de $\mathrm{f}^{*}$ (Luna, 1999). En las NTCC-2001 existe una ligera modificación en cuanto al cálculo del refuerzo mínimo con respecto a las NTCC-96. En las NTCC-2001 el refuerzo mínimo estará dado por la siguiente expresión: 


$$
A_{v}=0.25 \sqrt{f_{c}} * \frac{b_{w} s}{f_{y}}
$$
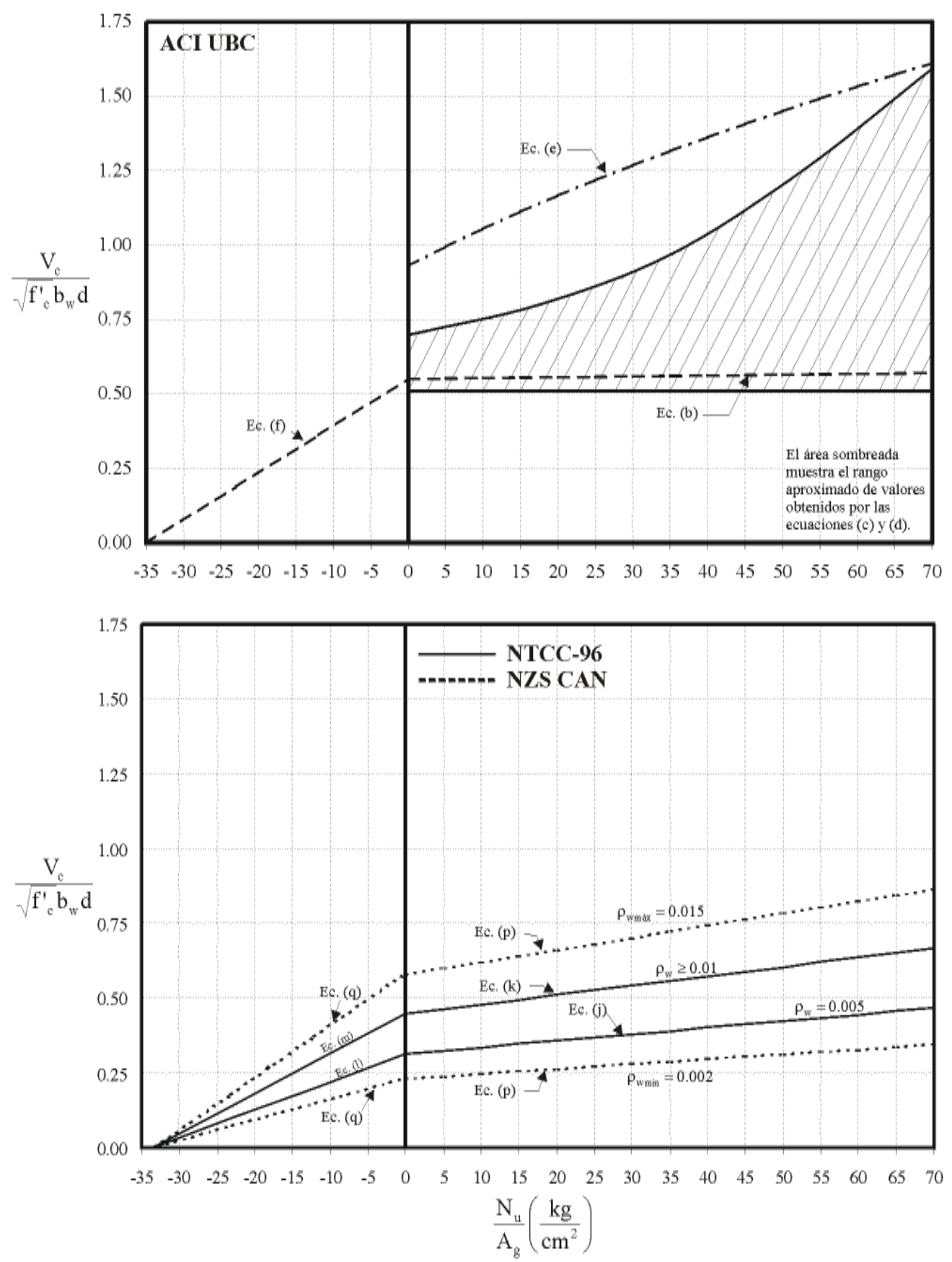

Figura 7. Comparación de las ecuaciones de diseño por cortante y carga axial. 
Tabla 4. Resistencia al cortante proporcionada por el acero de refuerzo.

\begin{tabular}{|c|c|c|}
\hline \multicolumn{2}{|c|}{ ACI UBC CAN NZS NTCC-96 } & AIJ \\
\hline $\mathbf{s}<$ & $\begin{array}{l}\text { Refuerzo Perpendicular: } \\
\qquad \begin{array}{l}\frac{\mathrm{d}}{2} \text { ó } 60 \mathrm{~cm} \\
\text { Si } \mathrm{V}_{\mathrm{s}}>1.1 \sqrt{\mathrm{f}_{\mathrm{c}}^{\prime} \mathrm{b}_{\mathrm{w}} \mathrm{d}} \\
\frac{\mathrm{s}}{2}\end{array}\end{array}$ & $\begin{array}{l}\qquad \underline{\text { Vigas }} \\
\text { La fuerza cortante permisible en vigas se } \\
\text { calcula como sigue: } \\
\qquad \mathrm{Q}_{\mathrm{A}}=\operatorname{bj}\left\{\alpha \mathrm{f}_{\mathrm{s}}+0.5_{\mathrm{w}} \mathrm{f}_{\mathrm{t}}\left(\mathrm{p}_{\mathrm{w}}-0.002\right)\right\}\end{array}$ \\
\hline $\begin{array}{l}\text { Refuerzo } \\
\text { Mínimo }\end{array}$ & $\begin{array}{l}\text { Cuando } \mathrm{V}_{\mathrm{u}}>\frac{1}{2} \mathrm{~V}_{\mathrm{c}} \\
\mathrm{A}_{\mathrm{v}}=3.5 \frac{\mathrm{b}_{\mathrm{w}} \mathrm{s}}{\mathrm{f}_{\mathrm{y}}}\end{array}$ & $\begin{array}{l}\text { donde: } \\
\qquad \alpha=\frac{4}{\frac{\mathrm{M}}{\mathrm{Qd}}+1} \quad \text { y } 1 \leq \alpha \leq 2\end{array}$ \\
\hline Refuerzo Máximo & $\mathrm{V}_{\mathrm{s}}<2.1 \sqrt{\mathrm{f}_{\mathrm{c}}^{\prime} \mathrm{b}_{\mathrm{w}} \mathrm{d}}$ & \\
\hline $\begin{array}{l}\text { Diseño del acero de } \\
\text { refuerzo por cortante }\end{array}$ & $\begin{array}{c}\text { Cuando } \mathrm{V}_{\mathrm{u}}>\frac{1}{2} \mathrm{~V}_{\mathrm{c}} \\
\text { Refuerzo perpendicular: } \\
\mathrm{V}_{\mathrm{s}}=\frac{\mathrm{A}_{\mathrm{v}} \mathrm{f}_{\mathrm{y}} \mathrm{d}}{\mathrm{s}} \\
\text { Refuerzo inclinado: } \\
\mathrm{V}_{\mathrm{s}}=\frac{\mathrm{A}_{\mathrm{v}} \mathrm{f}_{\mathrm{y}}(\operatorname{sen} \alpha+\cos \alpha) \mathrm{d}}{\mathrm{s}} \\
\text { Varillas misma distancia del } \\
\text { apoyo: } \\
\mathrm{V}_{\mathrm{s}}=\mathrm{A}_{\mathrm{v}} \mathrm{f}_{\mathrm{y}} \operatorname{sen} \alpha<0.8 \sqrt{\mathrm{f}_{\mathrm{c}}^{\prime} \mathrm{b}_{\mathrm{w}} \mathrm{d}} \\
\mathrm{V}_{\operatorname{arillas}} \text { distancia diferente del } \\
\text { apoyo: } \\
\mathrm{V}_{\mathrm{s}}=\frac{\mathrm{A}_{\mathrm{v}} \mathrm{f}_{\mathrm{y}}(\operatorname{sen} \alpha+\cos \alpha) \mathrm{d}}{\mathrm{s}}\end{array}$ & $\begin{array}{l}\text { Columnas } \\
\text { La fuerza cortante permisible en columnas } \\
\text { para cargas permanentes } \mathrm{Q}_{\mathrm{AL}} \mathrm{y} \text { para cargas } \\
\text { súbitas } \mathrm{Q}_{\mathrm{AS}} \text { se calcula como sigue: } \\
\qquad \mathrm{Q}_{\mathrm{AL}}=\mathrm{bj}_{\mathrm{AS}} \mathrm{s} \\
\left.\mathrm{Q}_{\mathrm{AS}}=\mathrm{b}_{\mathrm{s}}+0.5_{\mathrm{w}} \mathrm{f}_{\mathrm{t}}\left(\mathrm{p}_{\mathrm{w}}-0.002\right)\right\} \\
\text { donde: } \quad \frac{4}{\frac{\mathrm{M}}{\mathrm{Qd}}+1} \quad \mathrm{y} \quad 1 \leq \alpha \leq 2\end{array}$ \\
\hline \multicolumn{3}{|c|}{$\begin{array}{l}\text { Notas: } \mathrm{V}_{\mathrm{s}} \text {, resistencia nominal al cortante proporcionada por el acero de refuerzo; } \mathrm{V}_{\mathrm{c}} \text {, resistencia nominal al } \\
\text { cortante proporcionada por el concreto; } \mathrm{Vu} \text {, fuerza de cortante factorizada; } \mathrm{f}_{\mathrm{y}} \text {, resistencia especificada a la } \\
\text { fluencia del acero de refuerzo; } \mathrm{f}_{\mathrm{c}} \text {, resistencia especificada a compresión del concreto; } \mathrm{d} \text {, peralte del elemento; } \\
\mathrm{s} \text {, espaciamiento del acero de refuerzo por cortante; } \mathrm{A}_{\mathrm{v}} \text {, área de acero de refuerzo por cortante dentro de una } \\
\text { distancia } \mathrm{s} ; \mathrm{b}_{\mathrm{w}} \text {, ancho del alma de la viga; } \alpha \text {, ángulo comprendido entre los estribos inclinados y el eje } \\
\text { longitudinal del elemento. Unidades de esfuerzo en } \mathrm{kg} / \mathrm{cm}^{2} \text {, de área en } \mathrm{cm}^{2} \text {, de fuerza en kg y dimensiones en } \\
\mathrm{cm} \text {. }\end{array}$} \\
\hline
\end{tabular}


El cambio se debe a que de esta manera el refuerzo mínimo dependerá de la resistencia nominal del concreto a compresión, tomando en cuenta que la expresión anterior se formuló para concretos "normales" con resistencias nominales f ' ${ }_{c}$ entre $200 \mathrm{~kg} / \mathrm{cm}^{2}$ y $250 \mathrm{~kg} / \mathrm{cm}^{2}$ y, de hecho, el valor fijo de 3.5 de la propuesta de las NTCC-96 corresponde a una $\mathrm{f}_{\mathrm{c}}{ }_{\mathrm{c}}=250 \mathrm{~kg} / \mathrm{cm}^{2}$. La nueva ecuación pretende garantizar buenos diseños para concretos de mayor resistencia, que están siendo actualmente utilizados en México, donde resistencias nominales $\mathrm{f}_{\mathrm{c}}{ }_{\mathrm{c}}$ entre $300 \mathrm{~kg} / \mathrm{cm}^{2}$ y $450 \mathrm{~kg} / \mathrm{cm}^{2}$ ya son comunes en el diseño de estructuras de concreto en el Distrito Federal.

Especificaciones del AIJ para cortante

El AIJ no considera independientes las componentes de fuerza cortante que toma el concreto y la que toma el acero, sino que las agrupa y propone expresiones que incluyen ambas contribuciones, dichas expresiones se reproducen en la tabla 4 y se explican a detalle en AIJ-90, 1994 y Luna, 1999.

\section{ESPECIFICACIONES PARA MARCOS DÚCTILES}

El procedimiento de diseño en marcos resistentes a sismos consiste en detallar las vigas y las bases de las columnas, de tal manera, que durante un sismo severo pueda desarrollarse un mecanismo dúctil disipador de energía en esos puntos, mediante la formación de articulaciones plásticas, mientras se proporciona una reserva de resistencia suficiente, y mientras sea pequeña la probabilidad de que fluyan las columnas u ocurra una falla de cortante o adherencia (Park y Paulay, 1992).

Los reglamentos de diseño no son específicos respecto al nivel del factor de ductilidad de curvatura que debe disponerse en las secciones críticas, pero recomiendan los procedimientos de detallado que tienden a lograr una ductilidad adecuada. La ductilidad disponible de las secciones de concreto reforzado depende primordialmente del contenido de acero longitudinal de tensión y compresión, del contenido de acero transversal para el confinamiento del concreto y la restricción contra el pandeo de las varillas, de las resistencias del concreto y del acero, y de la magnitud de la carga axial (Park y Paulay, 1992).

\section{Requisitos generales}

\section{Propiedades de los materiales}

En los reglamentos estudiados se especifica una resistencia del concreto mínima a la compresión ( $\left.{ }^{\prime}{ }_{c}\right)$ de $200 \mathrm{~kg} / \mathrm{cm}^{2}$, excepto el AIJ que establece como mínimo $210 \mathrm{~kg} / \mathrm{cm}^{2}$. La propuesta de NTCC-2001 establecen ahora una resistencia mínima $\mathrm{f}_{\mathrm{c}}{ }_{\mathrm{c}}=250 \mathrm{~kg} / \mathrm{cm}^{2}$. El ACI, CAN y UBC especifican un límite máximo de $280 \mathrm{~kg} / \mathrm{cm}^{2}$ para $\mathrm{f}_{\mathrm{c}}$ c únicamente para concreto de agregado ligero. El reglamento NZS propone un valor máximo de $560 \mathrm{~kg} / \mathrm{cm}^{2}$ y el AIJ de $360 \mathrm{~kg} / \mathrm{cm}^{2}$. Las NTCC-96 no establecen un valor máximo de f ' $c$; sin embargo, la propuesta de NTCC-2001 
establecen un límite de $550 \mathrm{~kg} / \mathrm{cm}^{2}$ para el diseño de estructuras con un factor de comportamiento sísmico $\mathrm{Q}=4$.

Se establece en los reglamentos que las barras longitudinales de vigas y columnas deberán tener fluencia definida, bajo un esfuerzo que no exceda el esfuerzo de fluencia en más de 1300 $\mathrm{kg} / \mathrm{cm}^{2}$, y su resistencia real debe ser por lo menos igual a 1.25 veces su esfuerzo real de fluencia. El NZS estipula que el esfuerzo especificado de fluencia del acero de refuerzo utilizado en zonas donde potencialmente se presentará una articulación plástica, no deberá exceder los $4200 \mathrm{~kg} / \mathrm{cm}^{2}$. Factores de reducción de resistencia

Se mantienen básicamente los mismos valores que se plantearon en la sección de especificaciones generales para marcos, salvo algunos casos en los que dicho factor se modifica y que se explicarán más adelante en sus secciones específicas.

\section{Miembros a flexión}

Se considera un elemento trabajando a flexión aquel que soporta cargas axiales menores de $\frac{\mathrm{Ag}_{\mathrm{g}} \mathrm{f}_{\mathrm{c}}}{10}$, se incluyen trabes y aquellas columnas con cargas axiales pequeñas.

\section{Requisitos geométricos}

En la tabla 5 se muestran los requisitos geométricos de cada reglamento para elementos sujetos a flexión.

El ACI establece además que el ancho no debe ser mayor que el ancho del elemento de apoyo (medido en un plano perpendicular al eje longitudinal del elemento en flexión), más las distancias a cada lado del elemento de apoyo (ACI-95, 1997).

Las NTCC-96 estipulan que el ancho de la viga no excederá el ancho de las columnas a las que llega y que el eje de la viga no deberá separarse horizontalmente al eje de la columna más de un décimo de la dimensión transversal de la columna normal a la viga. Además, establece que en sistemas de viga y losa monolítica, la relación entre la separación de apoyos que eviten el pandeo lateral y el ancho de la viga no debe exceder de treinta (NTCC-96, 1996). Las NTCC2001 mantienen los mismos criterios en este respecto que las NTCC-96.

El criterio que relaciona el claro, el peralte y el ancho de elementos rectangulares sujetos a flexión en el código neozelandés (NZS), proviene de las limitaciones geométricas establecidas en el código británico (British Code of Practice CP 110). Dichas limitaciones están relacionadas con la degradación de rigidez que ocurre en un elemento a flexión durante ciclos reversibles de carga en el intervalo de fluencia y con la consideración que establece que una viga continua sujeta a momentos en sus extremos originados por carga lateral es equivalente a tener una viga en 
voladizo con un largo igual a dos tercios del largo de la viga continua y teniendo un factor de largo efectivo de 0.75 (NZS-82, 1982).

Los requisitos estipulados en el AIJ no son necesariamente basados en pruebas experimentales o desarrollos matemáticos, sino que algunos de ellos provienen de la experiencia práctica en ingeniería y de requisitos propuestos en códigos internacionales, considerando salvaguardar la ductilidad en las estructuras y la facilidad de construcción de las mismas. Se propone un ancho mínimo en las trabes de $25 \mathrm{~cm}$, con el objeto de prevenir el pandeo en el refuerzo a compresión y la falla por adherencia en el refuerzo a tensión, además de considerar también la facilidad en el colado (AIJ-90, 1994).

Tabla 5. Comparación de las especificaciones de flexión para marcos dúctiles.

\begin{tabular}{|c|c|c|c|c|c|c|c|}
\hline & ACI UBC CAN & \multicolumn{2}{|c|}{ NZS } & NTCC-96 & \multicolumn{3}{|c|}{ AIJ } \\
\hline $\begin{array}{l}\text { Requisitos } \\
\text { Geométricos }\end{array}$ & $\begin{array}{c}\mathrm{L}>4 \mathrm{~h} \\
\frac{\mathrm{b}}{\mathrm{d}}>0.3 \\
\mathrm{~b}>25 \mathrm{~cm} \\
\mathrm{~b} \leq \frac{3}{4} \mathrm{~d}\end{array}$ & \multicolumn{2}{|c|}{$\begin{array}{l}\frac{1_{n}}{b_{w}} \leq 25 \\
\frac{1_{n} h}{b_{w}^{2}} \leq 100\end{array}$} & $\begin{array}{l}\mathrm{L}>4 \mathrm{~h} \\
\frac{\mathrm{b}}{\mathrm{d}}>0.3 \\
\mathrm{~b}>25 \mathrm{~cm}\end{array}$ & \multicolumn{3}{|c|}{$\begin{array}{c}\text { b }>25 \mathrm{~cm} \\
\qquad \mathrm{~b}>\frac{\mathrm{d}}{4} \\
\text { en art. plástica. }\end{array}$} \\
\hline $\mathrm{A}_{\text {smín }}$ & $\begin{array}{c}\frac{0.8 \sqrt{f^{\prime}}}{f_{y}} b_{w} d \\
A_{s \text { mín }}>14 \frac{b_{w} d}{f_{y}}\end{array}$ & \multicolumn{2}{|c|}{$\frac{14.28 \mathrm{~b}_{\mathrm{w}} \mathrm{d}}{\mathrm{f}_{\mathrm{y}}}$} & $\frac{0.7 \sqrt{f_{c}^{\prime}}}{f_{y}} b d$ & \multicolumn{3}{|c|}{-} \\
\hline$\rho_{t \text { máx }}$ & $\leq 0.025$ & \multicolumn{2}{|c|}{$\frac{71.36}{f_{y}}$} & $\leq 0.75 \rho_{\mathrm{b}}$ & \multicolumn{3}{|c|}{$\leq 0.025$} \\
\hline $\mathrm{M}_{\mathrm{RE}}{ }^{+}$ & $\geq \frac{\mathrm{M}_{\mathrm{RE}}^{-}}{2}$ & \multicolumn{2}{|c|}{$\geq \frac{\mathrm{M}_{\mathrm{RE}}^{-}}{2}$ en toda la viga. } & $\geq \frac{\mathrm{M}_{\mathrm{RE}}^{-}}{2}$ & \multicolumn{3}{|c|}{$\geq \frac{\mathrm{M}_{\mathrm{RE}}^{-}}{2}$ en toda la viga. } \\
\hline $\mathrm{M}_{\mathrm{RCL}}{ }^{ \pm}$ & $\geq \frac{\mathrm{M}_{\mathrm{RE}}^{ \pm}}{4}$ & \multicolumn{2}{|c|}{$\geq \frac{\mathrm{M}_{\mathrm{RE}}^{ \pm}}{4}$} & $\geq \frac{\mathrm{M}_{\mathrm{RE}}^{ \pm}}{4}$ & \multicolumn{3}{|c|}{ - } \\
\hline \multirow[b]{3}{*}{$\mathrm{S}<$} & $\frac{\mathrm{d}}{4}$ & & & $\frac{\mathrm{d}}{4}$ & & A.P. & No A.P. \\
\hline & $8 \phi$ & $\frac{\mathrm{d}}{4}$ & $\frac{\mathrm{d}}{3}$ & $8 \phi$ & $(\# 3)$ & $15 \mathrm{~cm}$ & $20 \mathrm{~cm}$ \\
\hline & $24 \phi_{\mathrm{e}}$ & $\begin{array}{c}6 \phi_{1} \\
15 \mathrm{~cm}\end{array}$ & $\begin{array}{l}12 \phi_{\mathrm{lc}} \\
20 \mathrm{~cm}\end{array}$ & $\begin{array}{r}24 \phi_{\mathrm{e}} \\
30 \mathrm{~cm}\end{array}$ & $+(\# 3)$ & $\begin{array}{c}20 \mathrm{~cm} \\
8 \phi_{1} \\
\frac{\mathrm{d}}{3}\end{array}$ & $\begin{array}{c}30 \mathrm{~cm} \\
10 \phi_{1} \\
\frac{\mathrm{d}}{2}\end{array}$ \\
\hline \multicolumn{8}{|c|}{$\begin{array}{l}\text { Notas: } \mathrm{L} \text { y } \mathrm{l}_{\mathrm{n}} \text { representan el claro libre, b y } \mathrm{b}_{\mathrm{w}} \text { el ancho del elemento, h el peralte total y d el peralte efectivo. } \rho \text { representa el porcentaje de } \\
\text { refuerzo a tensión y } \rho^{\prime} \text { el porcentaje de refuerzo a compresión. } \mathrm{M}_{\mathrm{RE}}^{+} \text {, es el momento resistente positivo en el extremo de la viga, } \mathrm{M}_{\mathrm{RE}}^{\mathrm{R}} \text {, es } \\
\text { el momento resistente negativo en el extremo de la viga, } \mathrm{M}_{\mathrm{RCL}}^{ \pm} \text {, es el momento resistente positivo o negativo en el centro del claro. En la } \\
\text { sección de separación de refuerzo transversal, } \phi_{1} \text { es el diámetro de la barra longitudinal más delgada, } \phi_{\mathrm{lc}} \text { el diámetro de las barras } \\
\text { longitudinales a compresión y } \phi_{\mathrm{e}} \text { el diámetro del estribo. Unidades de esfuerzo en } \mathrm{kg} / \mathrm{cm}^{2} \text {, de área en } \mathrm{cm}^{2} \mathrm{y} \text {, dimensiones y diámetros en } \\
\mathrm{cm} \text {. }\end{array}$} \\
\hline
\end{tabular}

Algunos códigos internacionales proponen un ancho máximo en las vigas para asegurar que el anclaje del refuerzo a flexión de la viga se localice dentro de la columna. Sin embargo, el 
ancho de la columna es usualmente más grande que el de la trabe en la práctica japonesa y el refuerzo longitudinal de la viga se ubica dentro de la esquina del refuerzo longitudinal de la columna en la conexión trabe-columna, de ahí que no sea necesario proponer un límite superior en el ancho de las trabes (AIJ-90, 1994).

La limitación que relaciona el ancho y el peralte de la viga $\left(b>\frac{d}{4}\right)$ tiene que ver con la ductilidad. Una relación peralte-ancho muy grande implicaría problemas como pandeo del miembro. La deformación por cortante afecta el principio que establece que las secciones permanecen planas antes y después de la deformación cuando el claro de la trabe es corto en relación a su peralte. La relación del claro de cortante se toma en cuenta en los requisitos de cortante, por lo que no hay ningún límite relacionado con el claro de cortante en las especificaciones de flexión (AIJ-90, 1994).

\section{Refuerzo longitudinal}

En la tabla 5 se comparan los límites máximo y mínimo de acero longitudinal que se establecen en los diferentes reglamentos.

En la tabla 2, que compara las especificaciones generales para marcos, se observa que el porcentaje de refuerzo de tensión en un elemento sometido a flexión se limita a una fracción de la cantidad que produciría condiciones "balanceadas". En secciones sometidas sólo a flexión y cargadas monótonamente hasta la fluencia, este enfoque es factible porque la probabilidad de falla a la compresión puede estimarse confiablemente con el modelo de comportamiento adoptado para determinar el porcentaje de refuerzo correspondiente a una falla balanceada. El mismo modelo de comportamiento (debido a suposiciones incorrectas tales como la distribución lineal de deformaciones, el punto de fluencia bien definido para el acero, la deformación limitante de compresión en el concreto de 0.003, así como los esfuerzos de compresión en el concreto del recubrimiento) no puede describir las condiciones de un elemento en flexión sometido a inversiones de los desplazamientos muy dentro del intervalo inelástico. Por lo tanto, existen pocos razonamientos para continuar refiriéndose a "condiciones balanceadas" (como lo hacen las NTCC-96 y la propuesta de NTCC-2001) en el diseño de estructuras de concreto reforzado resistentes a sismos (ACI-95, 1997).

El recomendar limitar el porcentaje de acero a 2.5\% (tabla 5) se basa principalmente en condiciones de congestión de acero e, indirectamente en esfuerzos limitantes de cortante en las trabes de proporciones comunes (ACI-95, 1997). Para prevenir el desprendimiento del recubrimiento del concreto o que el acero de compresión fluya, el refuerzo a tensión en una viga no debe ser mayor de $2.5 \%$ (AIJ-90, 1994).

Todos los códigos estudiados establecen que al menos dos varillas deben disponerse en forma continua tanto arriba como abajo; sin embargo, el ACI no sugiere un diámetro mínimo explícito en esta sección, las NTCC-96 y las NTCC-2001 sugieren que sean del \#4, el NZS del \#5 
y el AIJ del \#6. Además, el AIJ sugiere que en el refuerzo a tensión no se utilicen más de dos lechos.

El ACI, las NTCC-96 y la propuesta de NTCC-2001 establecen que la resistencia a momento positivo en la cara de la junta no debe ser menor de la mitad a momento negativo proporcionada por esa cara de la junta $\left(\mathrm{M}_{\mathrm{RE}}{ }^{+} \geq \frac{\mathrm{M}_{\mathrm{RE}}^{-}}{2}\right)$. El NZS y el AIJ sugieren que no únicamente ocurra esto en las caras de las juntas, sino a lo largo de toda la viga.

Todos los reglamentos, excepto el AIJ, establecen que ni la resistencia a momento negativo ni a momento positivo, en cualquier sección a lo largo de la longitud del elemento, debe ser menor de un cuarto de la resistencia máxima a momento proporcionada en la cara de cualquier junta $\left(\mathrm{M}_{\mathrm{RCL}}{ }^{ \pm} \geq \frac{\mathrm{M}_{\mathrm{RE}}{ }^{-}}{4}\right)$ (ACI-95, 1997). En la tabla 5 se compara lo establecido por cada reglamento en este sentido.

El ACI, las NTCC-96 y la propuesta de NTCC-2001estipulan que sólo se permiten traslapes de refuerzo de flexión cuando se proporciona refuerzo transversal de confinamiento en la longitud de traslape. El espaciamiento máximo de refuerzo transversal que envuelve a las varillas traslapadas, no debe exceder de d/4 ó $10 \mathrm{~cm}$. No deben emplearse traslapes (ACI-95, 1997):

a) Dentro de las juntas.

b) Ni en una distancia de dos veces el peralte del elemento desde la cara de la junta.

c) $\mathrm{Ni}$ en las ubicaciones donde el análisis indique fluencia de flexión causada por desplazamientos laterales inelásticos del marco.

Los traslapes del refuerzo están prohibidos en regiones en las que se espera fluencia por flexión, porque dichos traslapes no se consideran confiables en condiciones de carga cíclica dentro del intervalo inelástico. El refuerzo transversal para los traslapes en cualquier ubicación es obligatorio por la posibilidad de pérdida del concreto del recubrimiento (ACI-95, 1997).

Las NTCC-96 y la propuesta de NTCC-2001 permiten explícitamente la utilización de paquetes de dos barras, lo que no admiten los demás reglamentos.

\section{Refuerzo transversal para confinamiento}

Los requisitos relacionados con el refuerzo transversal están dirigidos principalmente a confinar el concreto y mantener el apoyo lateral para las varillas de refuerzo en regiones en las que se espera fluencia, otros objetivos son resistir fuerzas cortantes y prevenir fallas por adherencia. Más adelante se tratarán los requisitos relacionados con la fuerza cortante. 
El ACI, las NTCC-96 y la propuesta de NTCC-2001 establecen que se deben disponer estribos en las siguientes zonas de los elementos de marco, refiriéndose implícitamente a las regiones potenciales de ocurrencia de articulación plástica. El AIJ y el NZS se refieren a éstas explícitamente (ACI-95, 1997):

a) En una longitud igual a dos veces el peralte del elemento, medida desde la cara del elemento de apoyo hasta la mitad del claro, en ambos extremos del elemento en flexión.

b) En longitudes iguales a dos veces el peralte del elemento en ambos lados de una sección donde puede ocurrir fluencia por flexión en conexión con desplazamientos laterales inelásticos del marco.

El inciso a) se refiere obviamente a una condición de carga lateral y el caso b) se refiere a elementos con resistencia variable a lo largo del claro, o a elementos para los que la carga permanente representa una gran proporción de la carga total de diseño, ya que pueden ocurrir concentraciones de rotación inelástica dentro del claro. Cuando se prevé una condición de este tipo, debe proveerse refuerzo transversal, también en regiones en las que se espera fluencia (ACI95, 1997).

El primer estribo deberá colocarse a no más de $5 \mathrm{~cm}$ de la cara del miembro de apoyo (ACI-95, 1997). El espaciamiento máximo de los estribos no debe exceder los valores mostrados en la tabla 5 para cada código. El reglamento neozelandés propone separaciones diferentes dependiendo del caso a) o b) tratados anteriormente y el reglamento japonés plantea diferencias dependiendo si se trata o no de una articulación plástica y si se utilizan estribos del \#3 o mayores. El diámetro mínimo sugerido para los estribos es de $7.9 \mathrm{~mm}$ (\#2.5) en las NTCC-96 y la propuesta de NTCC-2001, $6.4 \mathrm{~mm}$ (\#2) en el NZS y $6.4 \mathrm{~mm}$ (\#2) en el AIJ, el ACI no especifica un valor mínimo en esta sección, sin embargo en los requisitos generales el diámetro mínimo es de $9.5 \mathrm{~mm}(\# 3)$.

\section{Requisitos para fuerza cortante}

Los elementos que trabajan principalmente a flexión se dimensionarán de manera que no se presente falla por cortante antes que puedan formarse las articulaciones plásticas en sus extremos de acuerdo tanto con las NTCC-96 como por la propuesta de NTCC-2001.

\section{$\underline{\text { Fuerzas de diseño }}$}

El ACI, las NTCC-96, las NTCC-2001 y el NZS proponen que la fuerza cortante de diseño se obtenga del equilibrio del miembro entre caras de apoyos; se deberá suponer que en los extremos actúan momentos del mismo sentido valuados con las propiedades del elemento en esas secciones, sin factores de reducción, y con el esfuerzo en el acero de tensión al menos igual a $1.25 \mathrm{f}$. A lo largo del miembro actuarán las cargas gravitacionales correspondientes multiplicadas

por el factor de carga, según las NTCC-96 y las NTCC-2001. El NZS establece que los 
momentos que actúan en los extremos deberán calcularse considerando sobrerresistencia y no establece ningún método específico como lo hacen el ACI, las NTCC-96 y NTCC-2001.

Las NTCC-96 proponen un método alternativo para dimensionar y consiste en utilizar la fuerza cortante de diseño obtenida del análisis empleando un factor de resistencia, $\mathrm{F}_{\mathrm{R}}$, de 0.6 en lugar de 0.8 (NTCC-96, 1996), criterio que mantienen las NTCC-2001.

Con el procedimiento optativo se pretende obtener el mismo resultado que con el general, es decir, evitar que la viga falle por fuerza cortante antes que se formen las articulaciones inelásticas en los extremos. El procedimiento optativo es más sencillo, aunque como suele suceder en estos casos, puede conducir a un mayor consumo de acero en estribos ("Comentarios", 1991). El procedimiento optativo no sólo conduce a un mayor consumo de acero sino que también propicia, con la disminución del factor de resistencia $F_{R}$ a 0.6, un posible aumento de las secciones requeridas, como se ha demostrado en estudios recientes donde se han comparado los diseños de marcos dúctiles conforme a las NTCC-96 utilizando tanto el método riguroso como el optativo (Tena et al., 1997 y Luna, 1999).

\section{$\underline{\text { Refuerzo transversal }}$}

El refuerzo transversal en las zonas potenciales de formación de una articulación plástica se deberá dimensionar para resistir la fuerza cortante calculada de acuerdo al punto anterior, despreciando la contribución del concreto en la resistencia a fuerza cortante $\left(\mathrm{V}_{\mathrm{c}}=0\right)$ cuando ocurran las siguientes condiciones de acuerdo a cada reglamento:

a) En cualquier combinación de carga en las que intervengan las fuerzas sísmicas (NZS).

b) $\mathrm{Si} \mathrm{P}_{\mathrm{u}} \leq 0.10 \mathrm{f}^{\prime}{ }_{\mathrm{c}} \mathrm{A}_{\mathrm{g}}(\mathrm{CAN})$.

c) La fuerza cortante inducida por sismo representa la mitad o más de la resistencia al cortante máxima requerida dentro de esas zonas (ACI, NTCC-96 y NTCC-2001).

$V_{\text {TOTAL }}=V_{\text {C.GRAV. }}+V_{\text {SISMO }}$

$\mathrm{V}_{\mathrm{c}}=0$ si $\mathrm{V}_{\text {sismo }}>\mathrm{V}_{\text {C.GRAV }}$.

d) La fuerza a la compresión axial factorizada incluyendo los efectos de sismo es menor que $\mathrm{A}_{\mathrm{g}} \mathrm{f}$ 'c/20 (ACI).

Se ha demostrado en estudios experimentales de elementos de concreto reforzado sujetos a carga cíclica que se requiere más refuerzo por cortante para garantizar una falla por flexión si el elemento es sujeto a desplazamientos alternantes no lineales, que si el elemento es cargado solamente en una dirección. El incremento necesario de refuerzo por cortante es mayor en el caso de carga no axial. Esta observación se refleja en las especificaciones al eliminar el término que representa la contribución del concreto a la resistencia por cortante (ACI-95, 1997). 
Se supone que la contribución del concreto al esfuerzo cortante es imperceptible en zonas de articulaciones plásticas de vigas, de ahí que el refuerzo transversal sea requerido para tomar toda la demanda de cortante. Las regiones diferentes a las articulaciones plásticas deberán ser diseñadas normalmente con las contribuciones del concreto y del acero. Si la contribución del concreto se va a considerar nula debido a una combinación en la que intervienen fuerzas sísmicas, deberá permanecer nula para cualquier otro tipo de combinación (NZS-82, 1982).

Las especificaciones del AIJ para cortante en vigas se mostrarán en la siguiente sección debido a que coinciden con las planteadas para columnas.

\section{Miembros a flexocompresión}

Todos los reglamentos consideran un elemento trabajando a flexocompresión a aquel que soporta cargas axiales mayores de $\frac{\mathrm{A}_{\mathrm{g}} \mathrm{f}_{\mathrm{c}}}{10}$.

\section{Requisitos geométricos}

En la tabla 6 se muestran los requisitos geométricos de cada reglamento para elementos sujetos a flexocompresión. Básicamente las disposiciones son las mismas; sin embargo, el NZS mantiene su filosofía respecto al dimensionamiento que muestra en trabes, mientras que las NTCC-96 y las NTCC-2001 incorporan un par de requisitos más que parecen basarse en el reglamento neozelandés. Las razones para pedir un mínimo en la dimensión transversal de una columna son las siguientes ("Comentarios", 1991):

a) Hacerlas menos vulnerables a errores constructivos, a impactos accidentales y a excentricidades accidentales de otra índole.

b) Facilitar la colocación del refuerzo y del concreto, así como lograr cumplir con los recubrimientos necesarios sin disminuir demasiado la relación del área del núcleo al área transversal total.

La intención de que el área de la sección transversal sea al menos igual a $\frac{\mathrm{P}_{\mathrm{u}}}{0.5 \mathrm{f}_{\mathrm{c}}^{\prime}}$ es garantizar una cierta capacidad de giro en zonas de la columna donde llegaran a formarse articulaciones plásticas, la capacidad de giro inelástico en una columna aumenta al disminuir la relación $\frac{\mathrm{P}_{\mathrm{u}}}{\mathrm{A}_{\mathrm{g}} \mathrm{f}_{\mathrm{c}}{ }_{\mathrm{c}}}$ (“Comentarios", 1991).

Es conveniente hacer notar que esta disposición debería aparecer como una restricción de la carga axial de diseño más que una limitación de tipo geométrico, ya que en la práctica es común la utilización de programas comerciales de análisis estructural como el ETABS, el RC Buildings y el STAAD-III, que contienen programas de diseño de estructuras de concreto basados en el reglamento del ACI, y dado que esta es una diferencia importante en el 
procedimiento de diseño respecto a las NTCC-96 y las NTCC-2001, esta disposición geométrica pasa prácticamente inadvertida en la práctica de diseño estructural en México. Si se realizara la modificación que se propone, resultaría más difícil que se pasara por alto una disposición que afecta directamente a un elemento mecánico, que la que afecta a una condición geométrica como se establece actualmente.

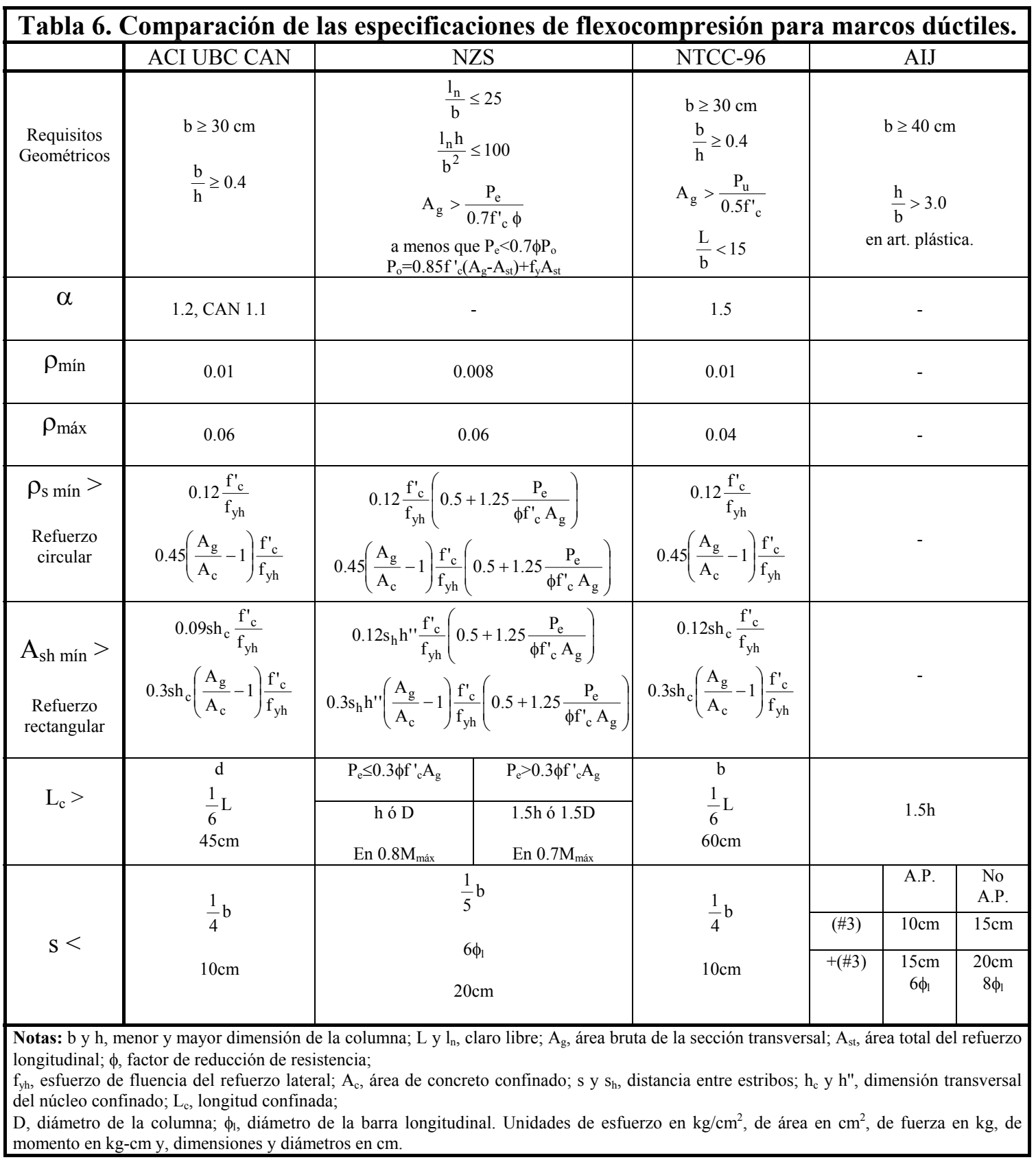


El ACI establece que las restricciones geométricas en elementos a flexocompresión se derivan de la práctica previa (ACI-95, 1997), es decir, a la tradición de uso. Sin embargo, los comentarios a las NTCC-96 las justifican técnicamente de la siguiente manera: Se pide que la relación entre la dimensión transversal mayor de la columna y la menor no exceda de 2.5 , para que el elemento siga siendo propiamente una columna y no pase a tener características de muro con el consiguiente problema del pandeo lateral. Para evitar que los efectos de esbeltez lleguen a ser causa de una disminución significativa de la ductilidad general de la estructura, se adiciona el requisito de que la relación entre la altura libre y la menor dimensión transversal no exceda de quince ("Comentarios", 1991).

Se establece un límite superior en la carga axial de columnas, porque secciones cargadas fuertemente requieren una gran cantidad de refuerzo de confinamiento para lograr una ductilidad adecuada. Aún y cuando se provea una gran cantidad de refuerzo por confinamiento en secciones cargadas fuertemente, se llega a un punto en que la ductilidad de curvatura disponible es dudosa (NZS-82, 1982). El límite de $0.7 \phi \mathrm{f}_{\mathrm{c}}{ }_{\mathrm{c}} \mathrm{A}_{\mathrm{g}}$ es razonable para miembros con relaciones de acero longitudinal moderadas. Para miembros con relaciones de acero longitudinal más grandes, el límite menos conservador de $0.7 \phi \mathrm{P}_{\mathrm{o}}$ puede ser usado. Puede demostrarse que $0.7 \phi \mathrm{P}_{\mathrm{o}}$ es mayor que $0.7 \phi \mathrm{f}_{\mathrm{c}}^{\prime} \mathrm{A}_{\mathrm{g}}$ cuando $\frac{\mathrm{A}_{\mathrm{st}}}{\mathrm{A}_{\mathrm{g}}}$ excede $\frac{0.15}{\frac{\mathrm{f}_{\mathrm{y}}}{\mathrm{f}_{\mathrm{c}}^{\prime}}-0.85}(\mathrm{NZS}-82,1982)$.

Además, las NTCC-96 y las NTCC-2001 sugieren que, al dimensionar por flexocompresión, la fuerza axial debida al sismo se tome igual a 1.7 veces la calculada, cuando esto conduzca a un momento resistente menor (NTCC-96, 1996). Esta recomendación no está validada por estudios específicos donde se valoren sus repercusiones, como se discutirá más adelante.

\section{Resistencia mínima a flexión}

El ACI, UBC, CAN, las NTCC-96 y las NTCC-2001 establecen un valor mínimo de la resistencia a flexión para columnas, con el propósito de reducir la posibilidad de fluencia en éstas, dicha resistencia debe satisfacer la ecuación 5:

$\sum M_{e} \geq \alpha \sum M_{g}$

donde:

$\sum \mathrm{M}_{\mathrm{e}}=$ suma de los momentos, al centro de la junta, correspondiente a la resistencia de diseño a la flexión de las columnas que forman el marco en dicha junta.

$\sum \mathrm{M}_{\mathrm{g}}=$ suma de momentos al centro de la junta, correspondiente a las resistencias de diseño a la flexión de las vigas que forman el marco en dicha junta. 
$\alpha$ : factor que amplifica la suma de momentos de las vigas.

En la tabla 6 se hace una comparación reglamentaria respecto al valor de $\alpha$ y resulta evidente que el valor que las NTCC-96 estipulan es considerablemente mayor al de otros reglamentos norteamericanos, como el ACI, UBC y CAN, sin justificar esta diferencia en investigaciones analíticas o experimentales. Las NTCC-2001 establecen el mismo criterio que las NTCC-96 en este respecto.

Las resistencias a flexión deben sumarse de tal forma que los momentos de las columnas se opongan a los momentos de la viga. La condición debe cumplirse para los dos sentidos en que puede actuar el sismo (ACI-95, 1997).

Consideraciones para la obtención de la carga axial de diseño

Las NTCC-96 establecen que al calcular la carga axial de diseño para la cual se valúe el momento resistente, $\mathrm{M}_{\mathrm{e}}$, de una columna, la fracción de dicha carga debida al sismo se tomará igual a 1.7 veces la calculada a partir del análisis cuando esto conduzca a un momento resistente menor (NTCC-96, 1996), criterio que mantienen las NTCC-2001. Se pide incrementar setenta por ciento la carga axial debida al sismo para prever que la fuerza sísmica horizontal exceda de la obtenida dividiendo el coeficiente sísmico entre el factor de comportamiento sísmico, $Q=4$. Una de las razones para dividir entre $Q$ es el supuesto comportamiento elastoplástico de la estructura, pero éste se ve afectado por la sobrerresistencia de las vigas, la presencia de muros y por la nosimultaneidad en la formación de las articulaciones plásticas, todo lo cual conduce a que la fuerza lateral que toma el edificio sea creciente en la deformación lateral, y por consiguiente, a que aumenten los momentos de volteo y las cargas axiales en las columnas, incremento que no se toma en cuenta en el análisis. El incremento es particularmente importante en las columnas de los primeros entrepisos de edificios altos y esbeltos ("Comentarios", 1991).

El estudio al que está referido este comentario (Romero, 1991) fue motivado por las consideraciones que se exponen en el mismo y evalúa el comportamiento inelástico de edificios esbeltos. El objetivo principal del trabajo es evaluar los momentos de volteo que resultan de aplicar los criterios del Reglamento de Construcciones para el Distrito Federal de 1987 y sus Normas Técnicas Complementarias para Diseño por Sismo, para este fin se proponen tres edificios esbeltos de diecisiete niveles formados por marcos de concreto reforzado con diferentes relaciones de esbeltez y periodos fundamentales cercanos a dos segundos; se realizaron análisis inelásticos paso a paso únicamente de un marco por cada edificio, utilizando el acelerograma registrado en la Secretaría de Comunicaciones y Transportes en septiembre de 1985, los máximos momentos de volteo obtenidos de los análisis inelásticos se comparan con los que resultaron de aplicar el Reglamento y sus Normas para un análisis estático (fig. 8).

El resultado de dicha comparación es la obtención de cocientes para cada marco, que relacionan el máximo momento de volteo, en la base exclusivamente, correspondiente a la respuesta inelástica y el que se obtiene a partir del Reglamento, posteriormente se obtuvo un promedio de los cocientes de los tres marcos y el valor que resultó fue 1.72 (fig. 8). 

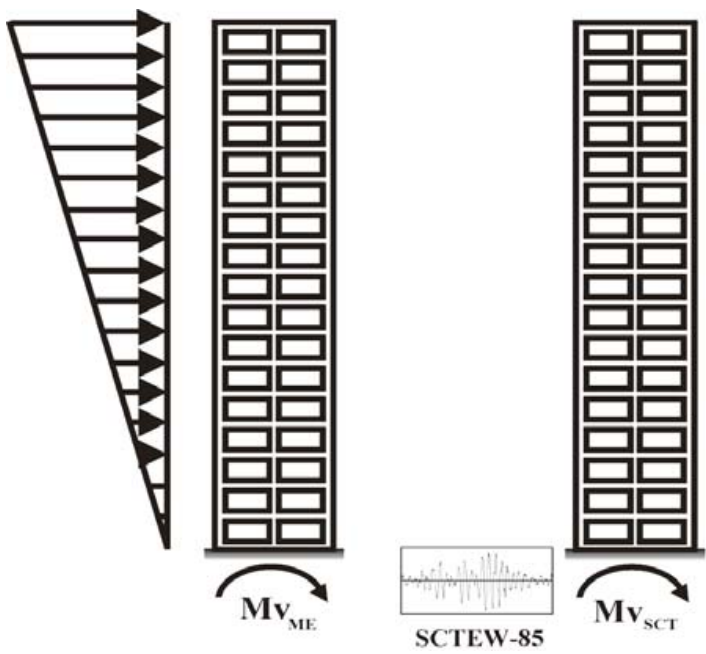

\begin{tabular}{|c|c|c|c|c|c|}
\hline Marco & $\begin{array}{c}\mathrm{T} \\
(\mathrm{s})\end{array}$ & $\begin{array}{c}\text { Relación } \\
\text { de } \\
\text { Esbeltez }\end{array}$ & $\begin{array}{l}\mathrm{Mv}_{\mathrm{ME}} \\
\text { (ton-m) }\end{array}$ & $\begin{array}{l}\mathrm{Mv}_{\mathrm{SCT}} \\
\text { (ton-m) }\end{array}$ & $\frac{\mathrm{Mv}_{\mathrm{SCT}}}{\mathrm{Mv_{ \textrm {ME } }}}$ \\
\hline 1 & 1.91 & 2.2 & 9655 & 78340 & 1.76 \\
\hline 2 & 1.67 & 3.3 & 8313 & 30810 & 1.72 \\
\hline 3 & 1.62 & 4.2 & 5062 & 16430 & 1.67 \\
\hline \multicolumn{5}{|c|}{ Promedio de cocientes $=$} & 1.72 \\
\hline
\end{tabular}

Figura 8. Obtención del factor 1.7 que modifica la carga axial debida al sismo en el cálculo de la carga axial de diseño para elementos a flexocompresión de marcos dúctiles (Romero, 1991).

Resulta difícil de creer que un estudio interesante, pero limitado en su planteamiento y enfoque, llegue a impactar las especificaciones de las Normas Técnicas Complementarias de Concreto. Es poco congruente generalizar a partir de un cociente de momentos de volteo en la base de marcos esbeltos, el que en todas las columnas de todos los entrepisos, sin importar que sean exteriores o interiores, se amplifique la carga axial por sismo en 1.7 veces, pero manteniendo constantes el valor de los momentos flexionantes y cortantes por sismo. Para los autores es claro que las diferencias entre uno y otro análisis no se pueden promediar con base en un cociente entre momentos de volteo. Asimismo, en el estudio de referencia, no se diseñaron nuevamente las estructuras en estudio aplicando la disposición que a bien han tenido imponer en las NTCC-96 y mantener en las NTCC-2001, para evaluar si con ello se observa un mejor desempeño que con el criterio con el cual se hizo el diseño de los marcos estudiados, los cuales, por cierto, no presentan fluencias que pudieran indicar un comportamiento inelástico insatisfactorio de las columnas de ningún entrepiso, es más, se observa en este estudio que las fluencias en los marcos analizados corresponden a un claro mecanismo de falla de viga-débil, columna-fuerte, donde existe una fluencia tan limitada de columnas que ni siquiera el autor consideró presentar gráficamente las magnitudes de sus rotaciones inelásticas, como si lo hace con lujo de detalle para las vigas (Romero, 1991). Además, el estudio es muy específico y sólo considera un acelerograma, SCT85-EW. Los autores de este trabajo no ven como los miembros del comité de las NTCC-96 pudieron interpretar dicho trabajo de la manera que lo hicieron, y pasaron por alto, entre otras cosas, que se deberían de haber considerado un mayor número de condiciones, acelerogramas y análisis diferentes, además de valorar el impacto de diseñar las columnas de estos modelos con el factor 1.7 actualmente propuesto en las NTCC-96. Es aún más sorprendente que este criterio se mantenga en las NTCC-2001. Ciertamente, la culpa de esta interpretación no se debe a Romero y su interesante trabajo (Romero, 1991). 
Además, el propio estudio de Romero (1991) reconoce que los resultados a los que se llegan impactan al diseño de la cimentación y al de las columnas de los niveles inferiores de edificios esbeltos.

En la fig. 9 se presenta la planta tipo de edificios de doce y quince niveles estudiados por Tena et al. (1997). Se analizan un par de columnas del primer nivel del edificio de 15 niveles que están en diferentes condiciones, una de ellas es columna de esquina y la otra es interior.

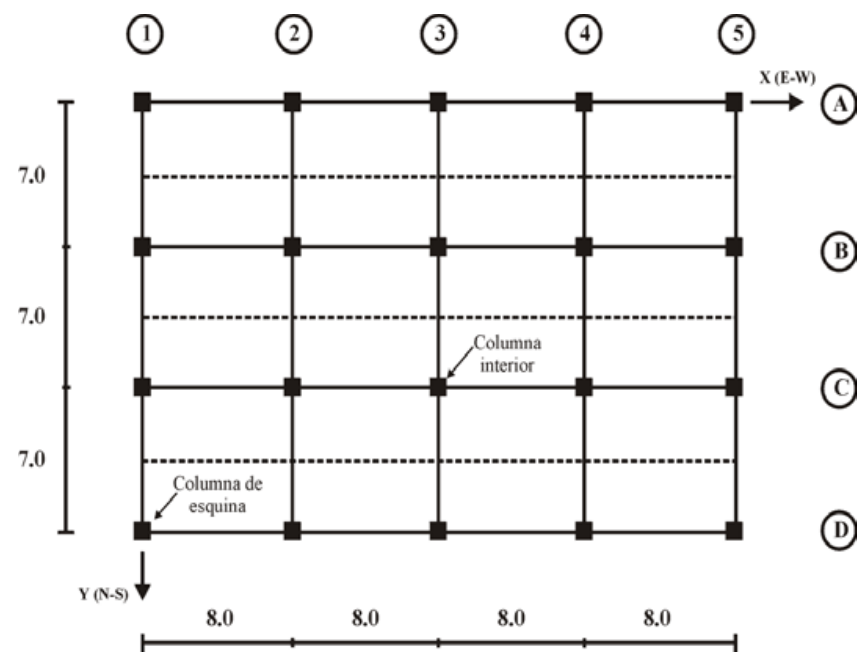

Figura 9. Planta tipo del edificio de 15 niveles E15Q3M1, acotaciones en m (Tena et al., 1997).

En la fig. 10 se muestran los diagramas de interacción de ambas columnas considerando respectivamente los diseños con el ACI y las NTCC-96, además se grafican los puntos de diseño y los puntos equivalentes a considerar el $70 \%$ de aumento en la carga axial debida al sismo. Es evidente que para la columna interior la aplicación de tal consideración en los puntos de diseño es imperceptible; sin embargo la diferencia en el diseño se debe al requisito geométrico delas NTCC-96 que establece que el área $\mathrm{A}_{\mathrm{g}}$, no será menor que $\frac{\mathrm{P}_{\mathrm{u}}}{0.5 \mathrm{f}_{\mathrm{c}}{ }_{\mathrm{c}}}$ para toda combinación de carga.

Así, con la única intención de hacer resaltar las diferencias en el diseño se mantiene la misma sección y armado en la comparación y se modifica el $\mathrm{f}$ ' $\mathrm{c}$, observándose que se requiere en el diseño de las NTCC-96 un aumento del 100\% en este parámetro para no modificar dichas condiciones. Para el caso de la columna de esquina, no únicamente se requiere un aumento del $100 \%$ en el $\mathrm{f}^{\prime}$, , sino que se precisa además de un incremento en el refuerzo para poder mantener la misma sección. En este caso nuevamente el requisito geométrico que limita al área de la sección rige en el diseño, haciendo inútil el requerimiento que establece el aumento del $70 \%$ en la carga axial debida al sismo. Al no existir esta disposición que complica notablemente el proceso de diseño en ningún otro reglamento vanguardista en el ámbito internacional, como por ejemplo, el ACI o el UBC, y afrontando la realidad que los programas de análisis y diseño de estructuras que más se utilizan en los despachos de ingeniería de México son de procedencia extranjera, principalmente estadounidense y española, y que este software incluye a los reglamentos norteamericanos ACI y UBC, y en el caso de los españoles, una versión de las NTCC-96 para 
marcos no dúctiles, es claro que los diseñadores mexicanos tienen que realizar prediseños prácticamente de manera manual, pues no cuentan con el software adecuado para implantar estas disposiciones, como si lo cuentan para otros reglamentos o para diseñar exclusivamente marcos no dúctiles. Tal vez esta sea otra razón por lo que en México se prefiere diseñar marcos no dúctiles, además de las expuestas por Rioboó (1995), puesto que los clientes no pagarían los costos adicionales de ingeniería que involucra aplicar esta disposición "novedosa" de las NTCC96, que desafortunadamente se mantienen en las NTCC-2001.
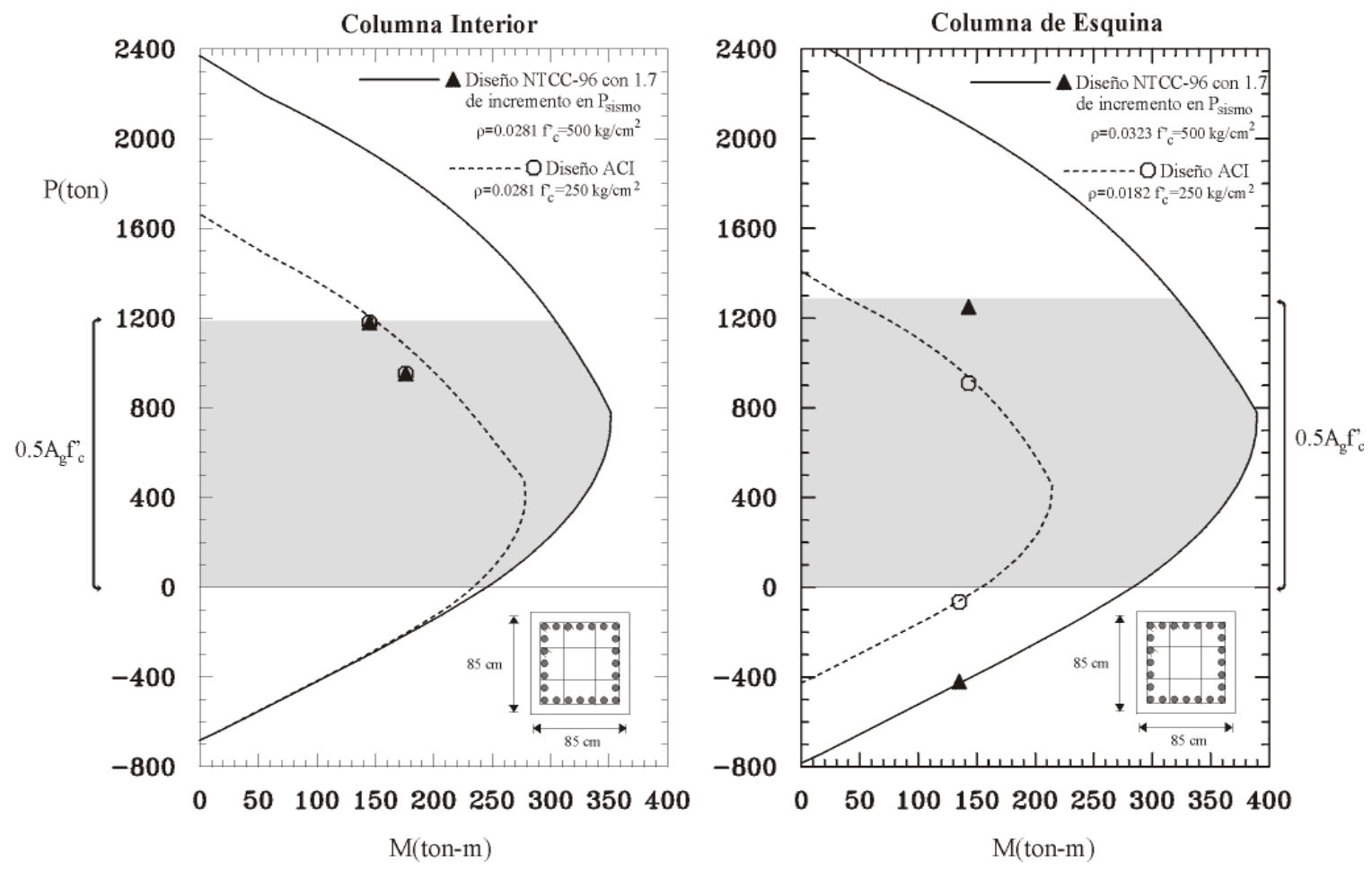

Figura 10. Diagramas de Interacción para mostrar el incremento propuesto por las NTCC-96.

Sería entonces conveniente considerar la posibilidad de limitar este requerimiento para que se utilizara únicamente en columnas exteriores de los niveles inferiores de marcos esbeltos y tomar en cuenta que se deben realizar un mayor número de investigaciones para poder generalizar y tener mayor certeza respecto al factor propuesto, además se debe comprobar que el requisito geométrico mencionado no rija sobre esta disposición, lo que parece ocurrir, convirtiéndola en una disposición totalmente obsoleta. La única modificación de las NTCC-2001 con respecto a las NTCC-96 y el incremento del setenta por ciento de la carga axial debida al sismo es que ahora se limita sólo para el diseño de estructuras con $\mathrm{Q}=4$, lo que libera de esta disposición sin sustento a los marcos dúctiles diseñados con $\mathrm{Q}=3$. Sin embargo, se considera a esta modificación claramente insuficiente e insatisfactoria a la luz de lo expuesto anteriormente.

Las NTCC-96 además proponen un procedimiento optativo en el que se establece que no será necesario revisar el cumplimiento de la condición relativa a las resistencias a flexión en los 
nudos, si las columnas se dimensionan por flexocompresión con un factor de resistencia de 0.6 (también en este caso la carga axial debida al sismo se modifica como se establece en la parte final relativa a los requisitos geométricos, NTCC-96, 1996). Este criterio se mantiene en las NTCC-2001 exclusivamente para el diseño de marcos dúctiles con $\mathrm{Q}=4$.

Sin embargo, se ha demostrado que con el método optativo no se llega a diseños comparables con los del método riguroso establecido por las NTCC-96, y que su comportamiento dinámico no puede considerarse equivalente (Tena et al., 1997; Luna, 1999). Existen otros estudios donde se ha encontrado que lleva a mecanismos de falla de columna débil, viga fuerte, sobre todo cuando se consideran sobrerresistencias tanto por confinamiento como por la contribución de las losas en la resistencia de vigas (Luaces, 1995). Por lo tanto, la modificación propuesta en las NTCC-2001 no parece ser la más acertada en la opinión de los autores.

El ACI sugiere que la resistencia a la flexión de la columna se debe calcular para la fuerza axial factorizada, congruente con la dirección de las fuerzas laterales consideradas, la que de como resultado la más baja resistencia a la flexión (ACI-95, 1997).

Considerando nuevamente la fig. 10, los valores para diseño de acuerdo con el ACI corresponden a los puntos de diseño en cada diagrama de interacción que tienen el valor relacionado con el momento flexionante más bajo.

El reglamento neozelandés propone reglas de diseño por capacidad para proteger las columnas de marcos resistentes a sismos, asegurándose de que dentro de lo posible ocurra un comportamiento columna fuerte-viga débil, dichas exigencias fueron introducidas primeramente en NZS 3101:1982 (NZS-82, 1982) y han permanecido prácticamente igual en NZS 3101:1995. En general, estos lineamientos involucran factores que toman en cuenta la sobrerresistencia a flexión en trabes, los efectos de modos de vibración superiores y la concurrencia de fuerzas sísmicas. Estos factores multiplican los momentos flexionantes y las fuerzas cortantes de las columnas, que se obtienen mediante un análisis elástico en el que están involucradas las fuerzas sísmicas de diseño. Los factores dependen de las condiciones del marco y son al menos iguales a 1.63. Las cargas axiales de diseño en columnas que se utilizan con los momentos flexionantes amplificados, para el diseño del refuerzo longitudinal de la sección a flexocompresión, deben resultar de las fuerzas cortantes aplicadas en las caras de las columnas provenientes de las cargas gravitacionales sobre las vigas y de las fuerzas cortantes ocasionadas por los momentos, que actúan en ambas direcciones, en las articulaciones plásticas formadas. Se permite un ajuste en los cortantes ocasionados por los momentos en las articulaciones plásticas, considerando la probabilidad de que no todas las articulaciones plásticas alcanzan su sobrerresistencia a flexión simultáneamente a lo largo del marco. Se utiliza un factor de reducción de resistencia $\phi=1.0$ para el diseño de columnas cuando se utilice este procedimiento (Park, 1997).

Es importante destacar la diferencia en la justificación de factores como el 1.63 propuesto por el reglamento neozelandés y el 1.7 propuesto por las NTCC-96, mientras que en el NZS se presenta una justificación transparente y razonada, congruente con su fílosofía de diseño, en las NTCC-96 dicho factor carece de suficientes argumentos técnicos y su inclusión en el Reglamento es injustificada y aún peor es el que se mantenga esta disposición en la propuesta de NTCC-2001. 


\section{Refuerzo longitudinal}

En la tabla 6 se comparan los límites mínimo y máximo de acero longitudinal que se establecen en los diferentes reglamentos. Las NTCC-96 coinciden con los valores del ACI, UBC y CAN en el porcentaje de refuerzo mínimo, el NZS establece el valor menor para ésta consideración. Para el porcentaje de refuerzo máximo las NTCC-96 especifican el valor más bajo.

Los diferentes reglamentos internacionales analizados no permiten la utilización de paquetes de barras, las NTCC-96 admiten explícitamente la utilización de paquetes de dos barras. Las NTCC-2001 mantienen el mismo criterio que las NTCC-96 en este respecto.

\section{Refuerzo transversal para confinamiento}

En la tabla 6 se comparan las cuantías volumétricas mínimas de refuerzo helicoidal o de estribos circulares, $\rho_{\text {smín }}$; las áreas mínimas de estribos rectangulares, $\mathrm{A}_{\mathrm{sh}}$; la longitud especificada para la articulación plástica probable, $1_{0}$; y las separaciones máximas de refuerzo transversal, $\mathrm{s}$, para cada reglamento. Como puede observarse, las NTCC-96 son únicamente más conservadoras que los otros reglamentos para la cuantía mínima del refuerzo transversal en columnas de núcleo rectangular; sin embargo, en la propuesta de NTCC-2001 se establece ahora el mismo criterio que para el reglamento ACI, entre otros.

Además, los reglamentos establecen que la distancia centro a centro, transversal al eje del elemento, entre ramas de estribos traslapados no será mayor de $35 \mathrm{~cm}$ (ACI), $45 \mathrm{~cm}$ (NTCC-96 y NTCC-2001), $20 \mathrm{~cm}$ (NZS) y entre grapas y ramas de estribos sobrepuestos no será mayor de 25 cm (NTCC-96 y NTCC-2001). Si el refuerzo consta de estribos sencillos, la mayor dimensión de éstos no excederá de $45 \mathrm{~cm}$ (NTCC-96 y NTCC-2001).

La cuantía de acero transversal de columnas en zonas potenciales de aparición de articulación plástica especificada en el reglamento neozelandés (NZS-82, 1982) está basada, al igual que los reglamentos del ACI, UBC, CAN y NTCC, en los requisitos del código de la Structural Engineers Association of California (SEAOC) de 1973, pero el NZS-82 modifica dicha cuantía para tomar en cuenta el nivel de carga axial (NZS-82, 1982; Luna, 1999).

\section{Requisitos para fuerza cortante}

Los elementos a compresión se dimensionarán de manera que no fallen por fuerza cortante antes que se formen articulaciones plásticas en sus extremos (NTCC-96 y NTCC-2001). Para esto, el ACI, CAN, UBC, las NTCC-96 y las NTCC-2001 proponen que la fuerza cortante de diseño se calcule del equilibrio del elemento en su altura libre, suponiendo que en sus extremos actúan momentos del mismo sentido, numéricamente iguales a los momentos resistentes de esas secciones, sin factor de resistencia y suponiendo una resistencia a la tensión de las varillas longitudinales de al menos $1.25 \mathrm{f}_{\mathrm{y}}$ y obtenidos con la carga axial de diseño que conduzca al mayor momento resistente (NTCC-96 y NTCC-2001). 
Además, las NTCC-96 y las NTCC-2001 consideran valuar la carga axial de diseño, la fracción de ella causada por el sismo se incrementará $70 \%$, cuando esto de lugar a un momento resistente mayor. Los comentarios respecto a este incremento están relacionados con lo tratado en secciones anteriores. Las NTCC-96 y NTCC-2001 establecen, sin embargo, que no será necesario que el dimensionamiento por fuerza cortante sea más conservador que el obtenido con la fuerza cortante de diseño proveniente del análisis y un factor de resistencia igual a 0.5 si se utiliza el método alterno. El ACI establece que en ningún caso la fuerza cortante de diseño será menor que el cortante factorizado determinado por el análisis de la estructura (ACI-95, 1997).

Las NTCC-96 y las NTCC-2001 sugieren en su procedimiento optativo que el dimensionamiento por fuerza cortante se realizará a partir de la fuerza de diseño obtenida del análisis, usando un factor de resistencia igual a 0.5. Como se comentó previamente, este procedimiento no solamente puede conducir a un mayor consumo de acero sino que también puede propiciar un aumento de las secciones requeridas llevando a diseños diferentes con respecto a los del método riguroso (Tena et al., 1997; Luna 1999).

El refuerzo transversal se deberá dimensionar para resistir el cortante despreciando la contribución del concreto cuando ocurran las siguientes condiciones:

a) La fuerza cortante inducida por sismo representa la mitad o más de la resistencia máxima al cortante requerida.

b) La fuerza axial factorizada a compresión, incluyendo los efectos por sismo, es menor que $\frac{\mathrm{Ag}_{\mathrm{g}} \mathrm{f}_{\mathrm{c}}}{20}$. plástica.

El ACI limita estas consideraciones a las longitudes de probable aparición de articulación

Es conveniente aclarar que dentro de las especificaciones relacionadas con marcos dúctiles existen además requisitos importantes vinculados con la revisión por cortante y adherencia de uniones viga-columna; sin embargo, el estudio de estos requerimientos rebasa el propósito fundamental de este trabajo.

\section{RESUMEN Y CONCLUSIONES}

El presente trabajo hace un análisis de las disposiciones de las Normas Técnicas Complementarias para Diseño y Construcción de Estructuras de Concreto (NTCC-96) y la Propuesta de Normas Técnicas Complementarias para Diseño y Construcción de Estructuras de Concreto (NTCC-2001) del Reglamento de construcciones para el Distrito Federal, basado en una comparación con diferentes reglamentos internacionales. Dicha comparación se enfocó en las disposiciones para marcos no dúctiles y marcos dúctiles contemplando las diferencias desde el punto de vista conceptual, numérico e intuitivo, intentando destacar las diferencias más 
relevantes entre los reglamentos internacionales y las NTCC-96 y la nueva propuesta NTCC2001, que a juicio de los autores son las siguientes.

Las NTCC-96 hacen disminuir el esfuerzo medio de compresión del bloque de esfuerzos como función de $\mathrm{f}_{\mathrm{c}}$, en lugar de su profundidad como lo hacen los demás reglamentos. Según los comentarios a las NTCC-96, este criterio se adoptó porque permite construir juegos de curvas de interacción que no dependen de $\mathrm{f}^{\prime}$ c para dimensionamiento de columnas, $\mathrm{y}$ conduce a resultados muy semejantes a los obtenidos con el ACI. Se analizaron los diagramas de interacción de una columna de $70 \times 70 \mathrm{~cm}$ con porcentajes de refuerzo mínimo y máximo, utilizando los respectivos bloques de esfuerzos equivalentes del ACI y las NTCC-96, y se observó que la zona de flexocompresión es distinta, debido a que el bloque propuesto por las NTCC-96 da origen a fuerzas de compresión y momentos flexionantes menores que la del bloque del ACI, y esto necesariamente redunda en una carga axial menor cuando se busca el equilibrio de fuerzas en la construcción de un diagrama de interacción. Por otro lado, se pudo observar también que los valores calculados para flexión pura y para flexotensión son sensiblemente iguales.

Se observó el efecto que tiene el incremento de la resistencia a compresión del concreto en el bloque de esfuerzos, construyendo diagramas de interacción normalizados respecto a la carga axial y momento máximos del ACI y haciendo variar el valor de $\mathrm{f}_{\mathrm{c}}{ }_{\mathrm{c}}$ de $250 \mathrm{~kg} / \mathrm{cm}^{2}$ a 400 $\mathrm{kg} / \mathrm{cm}^{2}$. En dichos diagramas se advirtió que, conforme aumenta el valor de $\mathrm{f}$ ' $\mathrm{c}$, la diferencia entre el ACI y las NTCC-96 en la zona de flexocompresión aumenta hasta en más de $20 \%$, y que esta diferencia es mayor en los casos en que se utilizó el porcentaje mínimo de acero de refuerzo, debido a que la contribución del acero de refuerzo es menor. La variación de la proporción del momento máximo de las NTCC-96 respecto al del ACI con el incremento de $\mathrm{f}_{\mathrm{c}}$ es menos significativa. Por estas razones, y tomando en cuenta que la propuesta del bloque equivalente de esfuerzos de las NTCC-96 era incompatible con concretos de alta resistencia, en las NTCC-2001 se propone un bloque equivalente de esfuerzos similar al del ACI, donde se diseña para un valor menor del esfuerzo de compresión medio, es decir, $\mathrm{k}_{3}=0.68$ para las NTCC-2001 mientras que $\mathrm{k}_{3}=0.85$ para el ACI, es decir, la diferencia estriba en que el ACI diseña con base en $\mathrm{f}^{\prime}{ }_{\mathrm{c}}$ mientras que las NTCC-2001 lo siguen haciendo en función de la resistencia nominal (reducida para fines de diseño) $\mathrm{f}^{*}$.

Además, las NTCC-96 y las NTCC-2001 tienen criterios más estrictos (conservadores) que afectan el diseño a flexocompresión de columnas, como por ejemplo, el establecer un porcentaje de refuerzo máximo $\left(\rho_{\max }\right)$ menor al que permiten los demás reglamentos.

A pesar de que los Comentarios de las NTCC-96 mencionan que sus formulaciones correspondientes a miembros sujetos a cortante, flexión y carga axial están basadas en el Reglamento ACI 318-83 y sus comentarios ACI 318R-83, se hizo evidente después de observar las expresiones de los reglamentos en discusión, que las formulaciones de las NTCC-96 referentes a cortante provienen más bien de las propuestas por el reglamento neozelandés (NZS), no solamente las que corresponden a flexión y compresión axial, sino aquellas relacionadas con flexión y flexotensión, quienes a su vez se basan en Comité ACI 426 de 1973. Se sugiere revisar la redacción de este documento en esas secciones para versiones futuras. Por otra parte, en las NTCC-96 y las NTCC-2001 se trabaja con un índice de resistencia reducido en función del valor 
de $\mathrm{f}^{*} \mathrm{c}$, mientras que los otros reglamentos lo manejan en función directa de $\mathrm{f}_{\mathrm{c}} \mathrm{y}$, además, el factor de reducción por resistencia también es menor, por lo que la valoración de la resistencia a cortante conforme a las NTCC-96 resulta ser en general más conservadora también con respecto a los otros reglamentos en estudio. Existen algunos cambios en las NTCC-2001 con respecto al diseño de vigas sin preesfuerzo con relación claro a peralte total $\mathrm{L} / \mathrm{h}>5$ con respecto a la fuerza cortante que toma el concreto en relación a las NTCC-96. Además, ahora la reducción de la fuerza cortante que toma el concreto en vigas con peralte mayor a $70 \mathrm{~cm}$ es gradual en las NTCC2001 y no abrupta como lo establecía las NTCC-96, además que el factor reductivo límite aumentó de 0.7 en las NTCC-96 a 0.8 en las NTCC-2001. Asimismo, en las NTCC-2001 se hace una modificación al refuerzo mínimo por tensión diagonal en vigas y columnas sin preesfuerzo, el cual depende ahora de la resistencia nominal del concreto, y pretende proteger el diseño de estructuras con resistencias nominales del concreto f ' ${ }_{\mathrm{c}}$ mayores a $250 \mathrm{~kg} / \mathrm{cm}^{2}$, ya que la expresión anterior de las NTCC-96 correspondía a este último valor, pues en ese entonces era poco común el uso de resistencias mayores.

Se hizo notar que la disposición que limita el área de la sección transversal en miembros a flexocompresión de marcos dúctiles debería aparecer como una restricción de la carga axial de diseño más que una limitación de tipo geométrico, ya que en la práctica es común la utilización de programas comerciales de análisis estructural que contienen programas de diseño de estructuras de concreto basados en el reglamento del ACI, y dado que esta es una diferencia importante en el procedimiento de diseño respecto a las NTCC-96 y las NTCC-2001, esta disposición geométrica pasa prácticamente inadvertida en la práctica de diseño estructural en México. Si se realizara la modificación que se propone, resultaría más difícil que se pasara por alto una disposición que afecta directamente a un elemento mecánico, que la que afecta a una condición geométrica como se establece actualmente.

Se hizo evidente que el criterio exclusivo de las NTCC-96 relacionado con la determinación de la carga axial en elementos a flexocompresión de marcos dúctiles, donde se incrementa el setenta por ciento de la carga axial debida al sismo, no está lo suficientemente justificado en investigaciones analíticas o experimentales, complicando y haciendo tedioso el proceso de diseño. Lamentablemente, este criterio se mantiene en las NTCC-2001, aunque ahora sólo se especifica para el diseño de marcos dúctiles con $\mathrm{Q}=4$. Se propone la posibilidad de revisar este requerimiento para que se utilice únicamente en casos muy específicos, como podrían ser las columnas en los extremos de los marcos de edificios irregulares de gran altura o edificios esbeltos, principalmente las de esquina, tomando en cuenta que deben realizarse un mayor número de investigaciones al respecto.

Atendiendo exclusivamente a criterios de resistencia, el método riguroso de diseño para marcos dúctiles de las NTCC-96 es claramente más conservador al propuesto por otros reglamentos, como por ejemplo el ACI y el UBC, sobre todo para el diseño de columnas, ya que establece un mayor factor que amplifica la suma de momentos de las vigas que llegan al nudo con respecto a la suma de momentos de las columnas, $\alpha$, establece valores más estrictos para los porcentajes de refuerzo máximo y mínimo en columnas, y además impone los requisitos adicionales discutidos párrafos atrás. Por lo tanto, las NTCC-2001 seguirán siendo también más conservadoras que los otros reglamentos internacionales de referencia, pero los autores reconocen 
que una comparación más racional de los reglamentos debería incluir también los factores y combinaciones de carga especificados por cada reglamento, lo que sale del alcance del presente estudio.

El método optativo de diseño para marcos dúctiles propuesto por las NTCC-96 sugiere un procedimiento más sencillo permitiendo la utilización de elementos mecánicos provenientes del análisis estructural e incorporando factores de resistencia reducidos, lo cual conserva la propuesta de NTCC-2001, aunque limitando su aplicación únicamente para diseños donde se use $\mathrm{Q}=4$. Sin embargo, dicho procedimiento no sólo conduce a un mayor consumo de acero como lo sugieren los comentarios a las NTCC-96, sino que también propicia, con la disminución de los factores de resistencia, un posible aumento de las secciones requeridas. Esta diferencia en el diseño respecto al método riguroso provoca que el comportamiento dinámico de ambos métodos no sea equivalente como se demuestra en los estudios de Tena et al., (1997) y Luna (1999). Incluso, existen estudios como el de Luaces (1995) que sugieren que el procedimiento optativo puede producir mecanismos de falla de naturaleza frágil.

En términos generales y atendiendo exclusivamente a criterios de resistencia (sin considerar factores y combinaciones de carga), se puede concluir que las NTCC-96 y la propuesta de NTCC-2001 en el rubro de marcos de concreto reforzado son conservadoras, particularmente en cuanto al diseño por cortante de todos sus elementos y el diseño de columnas a flexocompresión, sean parte o no de marcos dúctiles. El diseño para marcos dúctiles de las NTCC-96 no sólo es conservador, sino poco práctico y requiere de una revisión profunda que permita llegar a criterios razonables, seguros y prácticos que fomenten su aplicación en el diseño sismorresistente de estructuras de concreto en México. Al parecer, las NTCC-2001 no permitirán grandes mejoras en este respecto, a pesar de algunas modificaciones realizadas, que a juicio de los autores son aún insuficientes, pero que tal vez permitan y fomenten el diseño de marcos dúctiles con $\mathrm{Q}=3$, lo cual ya sería un avance.

\section{AGRADECIMIENTOS}

Este trabajo fue desarrollado en su parte inicial en el Centro de Investigación Sísmica A.C. con el patrocinio de la Secretaría General de Obras del Departamento del Distrito Federal, y continuado tanto en la Universidad Autónoma Metropolitana Azcapotzalco y el Instituto Mexicano del Petróleo. Los autores agradecen los valiosos comentarios hechos por los revisores anónimos del manuscrito original que permitieron mejorar el contenido del presente trabajo.

\section{REFERENCIAS}

ACI-95 (1997), "Reglamento para las construcciones de concreto estructural y Comentarios, ACI 318-95 y ACI 318R-95”, Instituto Mexicano del Cemento y del Concreto, A.C., México.

ACI-ASCE Committee 426 (1973), "The shear strength of reinforced concrete members Chapters 1 to 4", Proceedings ASCE, Journal of the Structural Division, ASCE, Vol 99, No ST6, junio. pp. 1091-1187. 
AIJ-90 (1994), “AIJ Structural design guidelines for reinforced concrete buildings”, Architectural Institute of Japan, Tokio.

"Comentarios, ayudas de diseño y ejemplos de las normas técnicas complementarias para diseño y construcción de estructuras de concreto, DDF" (1991), Publicación No ES-2, Instituto de Ingeniería, UNAM, noviembre.

Ghosh, S K, D A Fanella y B G Rabbat (1996), Notes on ACI 318-95 Building Code requirements for structural concrete with design applications, Portland Cement Association, sexta edición, Skokie, Illinois.

Habibullah, A (1992), “CONKER, concrete design”, Computers \& Structures Inc, Berkeley, California.

Luaces, F L (1995), "Sobrerresistencia en estructuras a base de marcos de concreto reforzado", Tesis de Maestría, División de Estudios de Posgrado, Facultad de Ingeniería, Universidad Nacional Autónoma de México, noviembre.

Luna, J L (1999), "Estudio de los criterios del Reglamento de construcciones para el Distrito Federal y sus normas técnicas complementarias para el diseño sísmico de edificios regulares con base en marcos de concreto reforzado", Tesis de Maestría, División de Estudios de Posgrado, Facultad de Ingeniería, Universidad Nacional Autónoma de México, julio.

MacGregor, J G y P Gergely (1977), "Suggested revisions to ACI Building Code clauses dealing with shear in beams", Journal of the American Concrete Institute, Vol 74, No 10, octubre, pp. 493-500.

NTCC-96 (1996), "Normas técnicas complementarias para diseño y construcción de estructuras de concreto", Gaceta Oficial del Departamento del Distrito Federal, marzo.

NTCC-2001 (2001), "Propuesta de normas técnicas complementarias para diseño y construcción de estructuras de concreto", http://www.smie.org.mx/articulos , abril.

NZS-82 (1982), "Code of practice for the design of concrete structures, NZS 3101", Standards Association of New Zealand, Private Bag, Wellington.

Park, R y T Paulay (1992), "Capítulo 5: Estructuras de concreto", Diseño de estructuras resistentes a sismos, Emilio Rosenblueth, editor, Instituto Mexicano del Cemento y del Concreto, A.C., segunda reimpresión, pp. 201-269.

Park, R (1995), "Recent structural concrete research and seismic design developments in New Zealand", Memorias, Seventh Canadian Conference on Earthquake Engineering, Montreal, Canadá, pp. 3-23.

Park, R (1997),'New Zealand code developments in the design and construction of reinforced concrete moment resisting frames for earthquake resistance", $U C B / E E R C-97 / 05$, The EERCCUREe Symposium in Honor of Vitelmo V. Bertero, January 31-February 1, Berkeley, California, pp. 9-16.

RCDF-93 (1993), "Reglamento de construcciones para el Distrito Federal”, Diario Oficial de la Federación, agosto.

“Revisor” (2001), Comunicación escrita de un revisor anónimo del manuscrito original. 
Rioboó, J M (1995), "Estructuras de concreto", Simposio Internacional La Ingeniería Civil a 10 Años de los Sismos de 1985, México, DF, septiembre, pp 123-127.

Romero, J E (1991), "Comportamiento inelástico de edificios esbeltos", Tesis de Maestría, División de Estudios de Posgrado, Facultad de Ingeniería, Universidad Nacional Autónoma de México, enero.

Tena, A, J L Luna, E Filloy y E del Valle (1997), "Evaluación de las recomendaciones del RCDF para el diseño por sismo de estructuras con marcos de concreto reforzado", Reporte FJBS/CIS97/04, Centro de Investigación Sísmica, A.C., Fundación Javier Barros Sierra, A.C., octubre.

UBC-97 (1997), “Uniform Building Code: 1997 edition”, International Conference of Building Officials, Whittier, California. 